\title{
EL DEBATE SOBRE LA REINTEGRACIÓN FORAL Y SOBRE SU MODO DE IMPLEMENTACIÓN EN NAVARRA EN \\ 1918-1919. LA POSTURA HISTORICISTA DE LOS FUERISTAS RADICALES DEL CARLISMO.
}

\begin{abstract}
DEBATE ON THE REINTEGRATION OF THE "FUEROS" AND ITS IMPLEMENTATION IN NAVARRE FROM 1918 TO 1919. THE HISTORICIST STANCE OF CARLIST RADICAL FUERISTS.
\end{abstract}

Fernando Mikelarena Peña.

Universidad de Zaragoza.

SUMARIO: I. INTRODUCCIÓN.- II. LA REINTEGRACIÓN FORAL. EL CARÁCTER DE SU REIVINDICACIÓN HASTA 1917. III. EL ESCENARIO POLÍTICO EN NAVARRA Y EL DECLIVE DEL CARLISMO. IV. EL DEBATE REINTEGRACIONISTA ENTRE EL VERANO DE 1917 Y LA PRIMAVERA DE 1918. V. EL DEBATE REINTEGRACIONISTA EN NAVARRA ENTRE NOVIEMBRE Y DICIEMBRE DE 1918. VI. EL DEBATE SOBRE CÓMO IMPLEMENTAR LA REINTEGRACIÓN FORAL PLENA. LA POSTURA DEL SECTOR MÁS RADICALMENTE FUERISTA DEL CARLISMO. VII. LA VIRTUALIDAD REAL DE LOS PLANTEAMIENTOS ANTERIORES EN LA ASAMBLEA DE 30 DE DICIEMBRE DE 1918 Y Y EL PROCESO POSTERIOR INMEDIATO. VIII. LA POSTURA TOMADA POR LA ASAMBLEA DE 30 DE DICIEMBRE. IX. LA RESISTENCIA DEL SECTOR MÁS RADICALMENTE FUERISTA A ABANDONAR SUS TESIS. X. EL ENFRENTAMIENTO ENTRE LOS DOS SECTORES DEL CARLISMO. XI. A MODO DE CONCLUSIÓN. MEMORIA Y DESMEMORIA EN EL DEBATE REINTEGRACIONISTA DE 1918.

Resumen: En este artículo se analiza el debate sobre la reintegración foral y sobre su modo de implementación en Navarra 1918. La novedad del análisis es la atención prestada a la postura historicista del sector más radicalmente fuerista del carlismo, hasta ahora no estudiada y que condicionó el debate. También se considera la memoria y la desmemoria implícitas en esa postura en la relación entre el constitucionalismo liberal y el constitucionalismo historicista navarro.

\begin{abstract}
This article outlines the controversy surrounding the reintegration of the "fueros" and its possible implementation in Navarre from 1918 to 1919. The novelty of the analysis is in the attention given to the historicist stance of the most radical sector of Carlism, which has not yet been studied and which undoubtedly determined the debate. The implicit memory and forgetfulness regarding the relationship between liberal constitutionalism and historicist constitutionalism from Navarre are also considered.
\end{abstract}

Palabras clave: Reintegración Foral, 1918, Constitución histórica, Navarra, Carlismo, Nacionalismo, Constitucionalismo Liberal. 
Key Words: Foral Reintegration, 1918, Historical Constitution, Navarre, Carlism, Nationalism, Liberal Constitutionalism.

\section{INT RODUCCIÓN.}

En este artículo se analiza el debate sobre la reintegración foral y sobre su modo de implementación en Navarra en 1918-1919, debate sobre el que se cumplen cien años. A diferencia de los puntos de vista adoptados por la bibliografia que se ha ocupado del tema, se presta atención a un aspecto hasta ahora no considerado por ningún autor: la postura del sector más radicalmente fuerista del carlismo en relación con los pasos a dar tras la derogación de la ley de 1839. Según ese sector, tal y como defendian los defensores del constitucionalismo historicista navarro de la primera mitad del siglo XIX y de acuerdo con su ideología absolutamente tradicionalista, la derogación de aquella ley debía ser acompañada en el caso de Navarra de la restauración de las Cortes estamentales navarras por cuanto solamente estas debian entender de las transformaciones institucionales a realizar en el escenario surgido de retroceder al contexto previo a 1839. El repaso a los pormenores del fracaso de esa postura en la asamblea de 30 de diciembre de 1918 y al proceso posterior se complementa con una profundización sobre la memoria y la desmemoria latentes implícitas en esa postura del sector más radicalmente fuerista del carlismo en lo que respecta respectivamente a la legitimidad, según la constitución histórica de Navarra, de la reclamación de restauración del marco desaparecido ochenta años atrás y a la imposibilidad de conciliación, según los criterios puestos en práctica por los doceañistas y por los propios liberales progresistas navarros, entre el constitucionalismo liberal y el constitucionalismo historicista navarro durante la primera mitad del siglo XIX.

\section{LA REINTEGRACIÓN FORAL. EL CARÁCTER DE SU REIVINDICACIÓN HASTA 1917.}

Con posterioridad a la promulgación de la ley de agosto de 16 de agosto de 1841, por la que Navarra dejaba definitivamente de ser un reino integrado dentro de la monarquía española para convertirse en una provincia dotada de una limitada autonomía administrativa y fiscal, la reintegración foral, entendida como el regreso al estatus politicoinstitucional previo a la ley de 25 de octubre de 1839 (ley que abría la puerta a la ulterior modificación de fueros), se planteó en diversas ocasiones, si bien nunca con un mínimo de concreción sobre cómo llevarla a cabo y sobre cómo salvar las incompatibilidades con el orden del Estado liberal español.

El primer momento en el que se esgrimió fue mes y medio después de la promulgación de la ley de agosto de 1841. En la fracasada sublevación de O'Donnell de octubre de aquel año, producto en Navarra de una alianza entre liberales moderados y carlistas, los alzados emitieron en sus proclamas promesas de reintegración foral. No obstante, desconocemos cómo se iba a compatibilizar la misma con la organización del estado liberal ya que no existe ningún texto que aclarara el contenido de aquellas. De hecho, podría sospecharse que aquellas promesas no fueron más que un banderín de enganche porque, con posterioridad 
a 1843, los liberales moderados, al mando a partir de entonces del gobierno del Estado, no hicieron ningún gesto reintegracionista, convirtiéndose más allá de dicha fecha el cuarentaunismo, o doctrina defensora del marco instaurado por la ley de 1841, en una realidad prácticamente indiscutida en Navarra. Lo que contrasta con la situación registrada en Vascongadas donde los moderados favorecerán una rectificación parcial de la total supresión de la foralidad llevada a cabo allí por Espartero, conformándose en esas provincias una situación de impasse hasta 1876 a causa de la negativa de las Diputaciones y de las Juntas Generales a emprender cualquier negociación si no se procedía previamente a la restauración foral plena ${ }^{1}$.

Tras 1843 y durante la segunda mitad del siglo XIX serán los carlistas los principales abanderados del reintegracionismo. A pesar de que los fueros no aparecen entre las motivaciones iniciales de la primera guerra carlista, el carlismo también empleó como estandarte el argumento foral a partir de 1835 en respuesta al fuerismo liberal. Posteriormente, la defensa de la España foral constituiría un eje importante en el programa ideológico carlista diseñado unos años después por Magín Ferrer, uno de los principales teóricos del movimiento: en su obra Las Leyes Fundamentales de 1845 proponía la resurrección, o instauración según los casos, de Cortes estamentales en en conjunto de España y en todos los territorios forales ${ }^{2}$. En el tercer cuarto del ochocientos el fuerismo carlista, que incluía la reivindicación reintegracionista, estuvo supeditado a la defensa del catolicismo, sobre todo por la influencia de los neocatólicos. En esta línea en 1868 Cruz Ochoa de Zabalegui, candidato a diputado a Cortes, proclamó en un manifiesto a los navarros la defensa del Altar y del Trono y la reintegración foral (postura restauracionista que fue calificada por Pablo Ilarregui, uno de los negociadores de la ley de 1841, como de "absurdo mayúsculo"), y un programa similar fue publicado por el conjunto de la candidatura carlista en 1869, pero sin dar detalles de cómo hacerlo ${ }^{3}$. Con todo, aunque en la Segunda Guerra carlista los fueros tuvieron aparentemente mayor peso que en la primera, las élites carlistas no dieron un carácter fuerista a la conflagración, insistiendo más bien en el cuestión religiosa $\mathrm{y}$ en el ultramontanismo, apareciendo aquellos débilmente, y en contadas ocasiones, en las proclamas ${ }^{4}$.

1 Fernando Mikelarena Peña, "La sublevación de O’Donnell de octubre de 1841 en Navarra", Historia Contemporánea, 38, 2009, pp. 239-275.

2 Magín Ferrer y Pons, Las Leyes Fundamentales de la Monarquía Española, según fueron antiguamente y según conviene que sean en la época actual, Barcelona, 1845, Volumen Segundo, pp. 97-147; María Cruz Mina Apat, "El carlismo y los Fueros", En "Por Dios, por la Patria y el Rey". Las ideas del carlismo. IV Jornadas de Estudios del Carlismo. 22-24 Septiembre 2010, Pamplona, Gobierno de Navarra, 2011, pp. 262-268.

3 Angel García-Sanz Marcotegui y Fernando Mikelarena Peña, "Españolismo, vasquismo y navarrismo foral: cambios y persistencias en la interpretación de la identidad navarra hasta 1936", Historia y Politica: ideas, procesos y movimientos sociales. 2, 1999, pp. 93-95; Angel, "Los liberales navarros y la cuestón foral tras la revolución de 1868", Huarte de San Juan. Geografia e Historia, 9, 2002, pp. 86 y 91.

$4 \quad$ María Cruz Mina Apat, “El carlismo y los Fueros”, op. cit., pp. 262-268 y 271-276; Gregorio Monreal Zia, "La Ley abolitoria de Fueros de 21 de julio de 1876 (antecedentes y paso por el Congreso)", Iura Vasconiae. Revista de derecho histórico y autonómico de Vasconia, 10, 2013, pp. 75-83. 
Posteriormente, los planteamientos reintegracionistas estuvieron ausentes en el movimiento de 1893-1894 conocido como Gamazada y que constituyó una eclosión catártica de la foralidad, entendida como defensa del marco instituído por la ley de 1841, contra las iniciativas de los ministros liberales de Hacienda Germán Gamazo y Amos Salvador que venían a recortar la autonomía fiscal navarra, al pretender introducir impuestos y contribuciones que ya existian o se iban a crear en las demás provincias de España. La protesta fue dirigida desde el primer momento por la Diputación navarra, quien logró el apoyo enardecido de la práctica totalidad de los estamentos e instituciones sociales y políticas, así como de los medios de prensa. Se produjeron concurridas manifestaciones populares en la capital y en otros municipios ${ }^{5}$.

El reintegracionismo foral regresó al debate político en Navarra en la segunda mitad del siglo $\mathrm{XX}$ de la mano de carlistas y del recién nacido nacionalismo. En el caso del carlismo respondia a los parámetros esbozados por Vázquez de Mella y otros próceres carlistas en el Acta de Loredán de 1897, primer texto programático del carlismo de la restauración, en el que se defendía el foralismo y el corporativismo territorial, social y político, pero contrario a cualquier separatismo y férreamente en pro de la unidad española. Con todo, la adhesión del carlismo a los fueros seguía estando en segundo lugar tras la defensa de la religión. De esta forma, "las alusiones a los fueros apenas aparecieron en la prensa carlista navarra hasta que en 1911 hizo su aparición el nacionalismo vasco en Pamplona". "Además, cuando aparecían generalmente tenían un aire nostálgico $\mathrm{y}$, en todo caso, nunca planteaban una estrategia concreta de ruptura con la situación existente", "como una suerte de sebastianismo"7. Por su parte, en el caso del nacionalismo vasco, su postura en cuanto a la articulación politicoinstitucional de Navarra con el Estado apostará firmemente por la derogación de la ley de 1839 y la reintegración foral, si bien sin ofrecer concreciones sobre cómo quedaría la conformación resultante de las instituciones, tal y como se puede comprobar con la lectura de su semanario, Napartarra, durante aquellos años.

El debate sobre la reintegración foral se acelerará, como veremos, en Navarra a partir de 1917, pero sobre todo, en los últimos meses de 1918, culminando en la Asamblea de Pamplona de 30 de diciembre de ese año, como reflejo del proceso autonomista catalán y de la campaña promovida por el nacionalismo vasco y también por la dinámica impulsada por un sector del carlismo que veía amenazada su situación hegemónica en la provincia.

\footnotetext{
Ángel García-Sanz Marcotegui y Fernando Mikelarena Peña, "Españolismo, vasquismo y navarrismo foral: cambios y persistencias en la interpretación de la identidad navarra hasta 1936", op. cit., pp. 103-105; Hermilio de Oloriz, La cuestión foral. Reseña de los principales acontecimientos ocurridos desde mayo de 1893 a julio de 1894, Pamplona, Imprenta Provincial, 1895.

María Cruz Mina Apat, "El carlismo y los Fueros”, op. cit., pp. 282-283.

7 Ángel García-Sanz Marcotegui, Caciques y politicos forales. Las elecciones a la Diputación de Navarra (1877-1923), Pamplona, El Autor, 1992, p. 314.
} 


\section{EL ESCENARIO POLÍTICO EN NAVARRA Y EL DECLIVE DEL CARLISMO.}

A lo largo de la mayor parte del periodo de la Restauración, el escenario politico en Navarra fue dominado por los partidos del Turno (es decir, los conservadores y los liberales). En las elecciones a diputados forales esos partidos consiguieron casi la mitad de los diputados en el conjunto del lapso 1877-1923, logrando el 50 por ciento o algo más en los subperiodos 1877-1888, 1890-1903 y 1917-1923. Sólo en 1905-1916 su nivel de representación en la Diputación descendió notoriamente, limitándose a 6 diputados. Los carlistas obtuvieron una representación relevante, pero minoritaria, en la mayor parte de las coyunturas: 28 diputados sobre 108 en el periodo global, 5 de 44 en 1877-1888, 7 de 26 en 1890-1903 y 3 de 16 en 1917-1923. Solamente entre 1903 y 1916, los carlistas, con 13 diputados de esa filiación sobre un total de 22 , fueron mayoria ${ }^{8}$. La imagen que se desprende de los resultados de las elecciones a elecciones a Cortes es bastante similar a la de los diputados forales elegidos. Entre 1891 y 1923 los 112 diputados de las 16 legislaturas comprendidas en aquel periodo se repartieron del siguiente modo: 46 conservadores, 41 carlistas, 13 liberales, 7 integristas y 5 nacionalistas vascos. Así pues, los partidos del Turno consiguieron más de la mitad de las actas en disputa, si bien es verdad que Navarra aparecía como un bastión del carlointegrismo en la medida en que de los 117 diputados carlistas e integristas totales que lograron escaño en el Congreso de los Diputados, 48 lo sacaron por nuestra provincia. Tan sólo entre 1901 y 1916, tal y como sucedió en las elecciones a diputados forales, el carlismo y el integrismo fueron mayoritarios en Navarra"9.

Se ha razonado la situación hegemónica de los carlistas en la Diputación entre 1905 y 1916, cuando se hablaba de la Diputación jaimista, más que por el argumento foralista (poco operativo en cuanto que, como se dijo, las alusiones a los fueros no abundaron en la prensa carlista), por la crisis del sistema de la Restauración, por el talante batallador y crítico del carlismo frente al mismo "y su actitud resistencialista y victimista frente a los sucesivos gobiernos", pero, sobre todo, por el factor político-religioso ${ }^{10}$, coincidiendo "con los años en que la cuestión religiosa ocupó un lugar central en el debate político"11.

Entre 1917 y 1923 se rompió la situación hegemónica del carlismo ya que no hubo ninguna fuerza que se impusiera claramente a las demás porque los liberales consiguieron cinco actas en las elecciones a diputados forales; los carlistas cuatro; los conservadores y los nacionalistas, tres cada grupo; y los integristas, una ${ }^{12}$. Las elecciones de diputados forales de marzo de 1917 para los dos diputados de Pamplona y para el diputado único de los partidos de Aoiz,

\footnotetext{
$8 \quad$ Ibid., p. 311.
}

$9 \quad$ María Cruz Mina Apat, "Elecciones y partidos politicos en Navarra, 1881-1923", en José Luis Garcia Delgado (ed.), La España de la Restauración. Politica, economía, legislación y cultura. Madrid, Siglo XXI, 1985, pp. 111-129.

10 Ángel García-Sanz Marcotegui, Caciques y politicos forales. Las elecciones a la Diputación de Navarra (1877-1923), op. cit., p. 314.

11 María Cruz Mina Apat, "Elecciones y partidos politicos en Navarra, 1881-1923", op. cit., p. 117.

12 Ángel García-Sanz Marcotegui, Diccionario Biográfico de los Diputados Forales de Navarra (1840-1931), Pamplona, Gobierno de Navarra, 1996, p. 49. 
Tafalla y Tudela supusieron (al ser elegidos los liberales Baztán, Badarán, Guelbenzu y Usechi, los carlistas Martínez Alsúa y Sanz y el integrista Juanmartiñena) "el fin de la hegemonía carlista que duraba desde principios de siglo y el paso a una Diputación mayoritariamente liberal" ya que "por primera vez desde hacía doce años la nueva Diputación que tomó posesión en mayo era de mayoría liberal y no carlista". La debilidad del carlismo fue agravada por la escisión mellista y el auge creciente de otras fuerzas políticas: el maurismo y el propio nacionalismo vasco ${ }^{13}$. En las elecciones legislativas de 1920 los jaimistas lograron recuperar el acta de Estella, pero fueron derrotados de nuevo en Aoiz, Tafalla y Tudela. Tras coaligarse con los nacionalistas en la Alianza Foral consiguieron un éxito muy relativo en las elecciones a diputados forales de Estella, Pamplona, Tafalla y Tudela de junio de 1921. De forma que la Diputación quedó conformada por un conservador (Goizueta), dos liberales (Guelbenzu y Usechi), dos jaimistas (Baleztena y Errea), un independiente (Oroz) y un nacionalista (Irujo) ${ }^{14}$.

La fuerte apuesta por el reintegracionismo foral realizada por los carlistas en 1918 tendría que ver con esa pérdida referida de su predominio en la escena politica navarra y para marcar terreno frente al nacionalismo en ascenso. Como veremos, los sectores más radicalmente fueristas del tradicionalismo realizaron una lectura del reintegracionismo muy apegada al historicismo y a la defensa de la Constitución Histórica navarra, desaparecida ocho décadas atrás, apostando por la resurrección de las Cortes estamentales, el marco políticoinstitucional y los derechos políticos de Antiguo Régimen de entonces jen la segunda década del siglo XX!, como primer paso para un hipotético aggiornamento posterior de las instituciones navarras. Obviamente esa perspectiva era de dificil asunción en una Navarra y en una España en la que la modernización se estaba acelerando en todos los planos: social, económico, ideológico y político. Y ni siquiera fue aceptada, según veremos, por otro sector del carlismo que adoptará una actitud de confluencia con las fuerzas conservadoras y liberales, poniendo en marcha una estrategia de bloqueo del movimiento reintegracionista. De esta forma, personalidades carlistas, de los partidos del turno y mauristas, pactarán una solución que pasará por la convocatoria de una asamblea el 30 de diciembre de 1918 en la que participará la inmensa mayoría de los ayuntamientos navarros y por la aprobación en ella de una resolución sumamente ambigua en relación con los propósitos iniciales, lo que hará que aquel movimiento fracasara durante los meses siguientes. A ese final también coadyuvará el final del proceso autonomista vascongado y catalán por la situación general española, así como la ruptura interna del carlismo.

\section{EL DEBATE REINTEGRACIONISTA ENTRE EL VERANO DE 1917 Y LA PRIMAVERA DE 1918.}

A partir del verano de 1917 y hasta noviembre de 1918 se produce en Navarra la primera fase del debate reintegracionista. En su inicio dicho debate surge como un eco de los movimientos de las diputaciones de las Vascongadas

13 Ángel García-Sanz Marcotegui, Caciques y politicos forales. Las elecciones a la Diputación de Navarra (1877-1923), op. cit.,pp. 272-273.

14 Ibid., pp. 284-297. 
que pretendian imitar el movimiento autonomista catalán, incentivadas por las visitas de Cambo a Vizcaya y Guipúzcoa. Si en julio de 1917 Cambó consiguió reunir a la mayoría de los diputados y senadores catalanes en una asamblea de parlamentarios en pro de un régimen de autonomía, representantes de las Diputaciones vascongadas se reunirán por iniciativa de Vizcaya durante toda la primera quincena de julio para tratar sobre la posibilidad de ampliación del autogobierno, viajando el día 10 a Pamplona para invitar a la Diputación navarra a una acción común de mejora de aquel para que cada corporación foral concretara lo que fuera de interés especial para cada de ellas. En la reunión, el vicepresidente de la Diputación foral de Navarra, el liberal Baztán, se mostró cauteloso por no haber tenido noticias previas de los propósitos perseguidos y "por ser muy especial la situación de esta provincia, en la que ya está en vigor el régimen de autonomía y descentralización económico-administrativa que tiene su origen y emana de la Ley paccionada de 16 de agosto de 1841 ", condicionando su alteración a los asesoramientos y estudios previos necesarios. Aunque en la reunión se acordó una segunda cita para el día 16, el día 12 el Consejo Foral Administrativo, un organismo consultivo creado en 1898 y compuesto por ex diputados provinciales, acordó aconsejar a la Diputación que no acudiera a esa segunda reunión reunión propuesta por las Vascongadas, a causa del temor de la mayoría del mismo a poner en peligro el marco derivado de la ley de 1841 y por las circunstancias políticas por las que atravesaba España.

En esa reunión del Consejo Foral Administrativo el carlista y exdiputado foral Joaquín Beúnza se desmarcó de la mayoría y preguntó por el grado de satisfacción con la ley de 1841 y por la interpretación y aplicación que de la misma hacía el Estado, y subrayó que Navarra deseaba ampliar su autonomía en términos que no ofrecieran peligro para la unidad de la Patria. Para Beúnza en pro de ese objetivo Navarra podía trabajar en unión de las Diputaciones Vascongadas siempre que precedieran "a toda gestión declaraciones del más ferviente españolismo de las cuatro Diputaciones y de que aplazaran éstas toda gestión en el sentido indicado, testimoniando de este modo sus sentimientos patrióticos y de amor a España, si hay otros asuntos nacionales que así lo aconsejen".

Finalmente la reunión del Consejo Foral Administrativo votó tres propuestas. La propuesta del exdiputado foral maurista y exsecretario de la Diputación, muy ligado a Diario de Navarra, Pedro Uranga Esnaola planteaba que se comunicara a las Diputaciones "Hermanas" de Vascongadas la justicia de sus aspiraciones, pero consideraba inoportuno formularlas en ese momentonpor la situación que atravesaba España. Una segunda moción del exdiputado maurista Félix Amorena, muy vinculado también a Diario de Navarra, era similar a la anterior, si bien señalaba que la Diputación expondría al Gobierno sus peticiones cuando lo estimase conveniente. Una tercera propuesta, defendida por el exdiputado foral jaimista Beúnza, recomendaba la asistencia de Navarra a la reunión con las Diputaciones vascas con el fin de que, unidas a las mismas, se ofreciesen al Gobierno tanto para todo "cuanto interese a la Patria española, así como para la solución de los graves problemas que las actuales circunstancias tengan planteados o puedan plantear" y, expresaba, asimismo, el deseo unánime de las cuatro Diputaciones de que, una vez que el Gobierno superase esos problemas que embargaban su atención "se resuelva en sentido favorable a las cuatro provincias el problema autonómico, teniendo en todo momento presente el 
régimen jurídico especial que diferencia a Navarra de las Vascongadas". A resultas de las recomendaciones del Consejo Foral Administrativo, la Diputación remitió una carta a Ladislao de Zabala, Presidente de la Diputación guipuzcoana, en la que se mostraba su apoyo a las aspiraciones autonomistas del País, pero rechazaba participar en las gestiones que proyectaban practicar las Diputaciones vascas "en atención a las dificultades notoriamente dificiles porque atraviesa la Patria, las cuales inducen a esta Diputación a aplazar toda demanda sobre dicho objeto, sin perjuicio de formularla cuando Navarra lo estime conveniente". A pesar de todo, tres diputados forales navarros (el vicepresidente Baztán y los dos diputados carlistas Javier Sanz y Francisco Martínez Alsúa) asistieron, a título particular, a la Asamblea de Vitoria, celebrada el día 16 de julio, en la que se acordó solicitar de los Poderes públicos, una "amplia autonomía que esté en consonancia con las constantes aspiraciones del país" y rogaron a los diputados navarros presentes en el acto que transmitiesen a la Diputación el deseo de "establecer una mayor aproximación entre las cuatro provincias que integran la región vascongada". Esa petición sería desatendida de nuevo por el Consejo Foral Administrativo a finales de julio, así como por la Diputación. Con todo, el diputado foral carlista Martínez Alsúa se separaría de la postura de los demás componentes de la corporación foral en su reunión del 3 de agosto y apoyó la acción conjunta de Navarra con las diputaciones vascongadas en el movimiento autonomista que, según él, debía finalizar en el restablecimiento absoluto del régimen foral anterior a la ley de 25 de octubre de 1839 "que mantenía robusta como nunca la nacionalidad española, al mismo tiempo que permitiría la vida propia y afirmaba la personalidad de todos los antiguos reinos y regiones de la península"15.

Con posterioridad, el movimiento reintegracionista en Navarra cobraría un segundo impulso en enero de 1918. El día 2 de ese mes el ayuntamiento de Pamplona acordaba apoyar una moción de la minoría nacionalista en el sentido de solicitar a las Cortes la reintegración foral, lo que fue apoyado por personalidades carlistas como Gabino Martínez, el conde de Rodenzo, etc., y diversos ayuntamientos navarros. Desde las elecciones municipales de noviembre de 1917 en Pamplona los liberales habian perdido el ayuntamiento y carlistas y nacionalistas coparon diez de las doce concejalias que se habian dirimido, conformándose la corporación municipal para 1918 por 13 concejales carlistas, tres nacionalistas, tres republicanos, un integrista, un socialista y 4 liberales o demócratas, quedando las dos restantes para un integrista y un republicano ${ }^{16}$. En abril el diputado a Cortes nacionalista por Navarra Manuel Aranzadi también solicitará en el Congreso de los Diputados "que nos devuelvan las facultades legislativas que teníamos y que la ley del 39 nos quitó, para entonces ponemos a

15 Idoia Estornés Zubizarreta, La construción de una nacionalidad vasca: el autonomismo de Eusko Ikaskuntza (1918-1931), Vasconia. Cuadernos de Historia-Geografia, 14, 1990, pp. 98-107 ; Jesús María Fuente Langas, "Antecedentes y consecuencias del fracasado proyecto de régimen foral de 1919", Tercer Congreso de Historia General de Navarra, Volumen III. El mundo de las Ideas, Pamplona, Sociedad de Estudios Históricos de Navarra, 1994; José María Jimeno Jurio, Navarra y Vascongadas (1917-1919). Reivindicaciones autonómicas y Reintegración Foral, Pamplona, Pamiela/Udalbide/Euskara Kultur Elkargoa, 2008, pp. 52-65.

16 José María Jimeno Jurio, Navarra y Vascongadas (1917-1919). Reivindicaciones autonómicas y Reintegración Foral, op. cit., pp. 80-96. 
la altura de la época actual, adaptándonos, con las instituciones nuestras, a las circunstancias presentes, siguiendo siempre el camino y el progreso de los tiempos", conseguido lo cual "nosotros seguiremos trabajando por la unión afectiva entre todas las regiones de España, que fue gloriosa mientras no fue centralista ni oprimió a los pueblos"17.

\section{EL DEBATE REINTEGRACIONISTA EN NAVARRA ENTRE NOVIEMBRE $Y$ DICIEMBRE DE 1918.}

Paralelamente al impulso al movimiento autonomista en Cataluña y en Vascongadas desde finales de $1918^{18}$, a partir de noviembre de 1918 se activa plenamente el debate reintegracionista en Navarra. La petición el 3 de noviembre de 1918 en el Congreso por parte de los diputados del PNV, el navarro Manuel Aranzadi entre ellos, de derogación de la ley de 1839 suscitó una polémica en la prensa sobre la legitimidad de aquellos para solicitar algo en nombre de Navarra. E1 22 de noviembre Diario de Navarra, el periódico maurista órgano de expresión de las élites navarras no carlistas, recogía una carta de Manuel de Aranzadi en la que expresaba su derecho como diputado a Cortes por Navarra para pedir la derogación de la ley de 1839, tal y como lo hizo en unión de los demás diputados nacionalistas, por pensar que la petición le corresponde a Navarra "de un modo indiscutible" y por pensar que se hacía "eco del sentir general en Navarra" porque "realmente, fuera de los mauristas y de los pocos amigos y comprometidos con los gobiernos que en estos años han tornado en el Poder, no sabemos de un solo navarro que se niegue a pedir la derogación de esa ley". Comentaba que tanto los carlistas como los integristas, los republicanos, los socialistas y los nacionalistas, querian la derogación de la ley de 1839. Diario de Navarra respondió a Aranzadi que les había molestado "no la proposición en sí misma, sino la actitud del señor Aranzadi, siempre unido a los bilbainos, siempre con la vista en Bilbao, siempre uniendo a Navarra con Vizcaya" y concluía diciendo que "Amigos de Vizcaya sí. Supeditados a ella o confundidos con ella no". También añadía que Aranzadi podía haber recabado el apoyo de los demás diputados a Cortes por Navarra como Pradera o Rodezno y que el resto de la prensa había criticado la actitud de los nacionalistas de hablar por Navarra.

La solicitud se había trasladado, además, para entonces a las instituciones navarras en razón del apoyo de los carlistas. El ayuntamiento de Pamplona acordó el 20 de noviembre de 1918 suscribir una solicitud de la mayoría jaimista en la que se pedía la derogación de la ley de 1839 "por los procedimientos que juzgue más eficaces" porque, considerando que el momento era el más conveniente y favorable para reclamar "la más amplia autonomía para Navarra", esta tenía "su fórmula concreta, sencilla y acabada en la derogación" de aquella Ley "y la consiguiente restauración de todos los organismos y fueros navarros". Se aceptó una enmienda del nacionalista Cunchillos de sustitución de las

17 Idoia Estornés Zubizarreta, La construción de una nacionalidad vasca: el autonomismo de Eusko Ikaskuntza (1918-1931), op. cit., p. 120.

18 Sobre el impulso al movimiento autonomista en cataluña durante esos meses finales de 1918 y los primeros de 1919, veáse Albert Balcells. El projecte d'autonomia de la Mancomunitat de Catalunya del 1919 i el seu context històric, Barcelona, Parlament de Catalunya, 2010. Sobre el movimiento autonomista en Vascongadas veáse Idoia Estornés Zubizarreta, La construción de una nacionalidad vasca: el autonomismo de Eusko Ikaskuntza (1918-1931), op. cit., pp. 139-149. 
palabras "la más amplia autonomía" por la de "reintegración foral". También se recogió una enmienda de otro concejal nacionalista, Lorda, en la que se invitaba a los ayuntamientos navarros a adherirse al acuerdo y que después se elevara el acuerdo a la Diputación.

A lo largo del mes siguiente 216 de los 269 ayuntamientos navarros se sumarán a la demanda del consistorio pamplonés.

\section{EL DEBATE SOBRE CÓMO IMPLEMENTAR LA REINTEGRACIÓN FORAL PLENA. LA POSTURA DEL SECTOR MÁS RADICALMENTE FUERISTA DEL CARLISMO.}

En el mismo número de 21 de noviembre de 1918 en el que informaba sobre el acuerdo del ayuntamiento de Pamplona de petición de la reintegración foral de Navarra a propuesta de la mayoría jaimista, El Pensamiento Navarro, el órgano de expresión del carlismo, se refería a los artículos publicados en Diario de Navarra unos días antes, el 15 y el 18. El periódico carlista rechazaba la propuesta del periódico conservador de que "una Junta, o lo que sea" tenga "atribuciones que solo podian tener unas Cortes constituyentes navarras". El Pensamiento Navarro se mostraba a favor de que Navarra pida la derogación de la ley de 1839 porque "la reintegración foral plena para todas las regiones, dentro de la unidad de la patria española, es un dogma en el programa tradicionalista".

Dos dias más tarde, el 22 de noviembre, El Pensamiento Navarro, en un artículo de réplica a otro de Diario de Navarra, aseguraba que las Cortes de Navarra deberían "de reunirse inmediatamente" tras la derogación de la ley de 1839 y recordaba que en aquel entonces estaban "acometiendo la resolución del mismo problema pueblos de Europa y España que solo tienen un vago recuerdo de haberse gobernado por sí mismos y que no saben exactamente, a la hora actual, la capacidad que tienen para hacerlo".

Asimismo, el 23 los editorialistas del periódico tradicionalista afirmaban que Diario de Navarra estaba en un error al creer que "las antiguas Cortes, tal como estaban constituídas, no encontrarán hoy un solo defensor en Navarra”, ya que en opinión de esa idea sería apoyada por "miles de ellos, todos los carlistas convencidos de que después de derogada la Ley de 25 de Octubre de 1839, el respeto a un Derecho establecido les impone acatar la autoridad de unas Cortes, cuya voluntad es superior a la suya. Sería absurdo que los fueristas empezasen a ejercitar sus derechos, vulnerando el escrito en los fueros". No obstante, el periódico jaimista reconocía que "naturalmente que no está en nuestras previsiones el que esas Cortes sean las que en definitiva desempeñen la función legislativa para la vida actual de Navarra" ya que "si así pensásemos, habria que llevarnos al Manicomio; pero afirmamos que esas Cortes, y no otras, son las que deben, con arreglo a Fuero, determinar cuál ha de ser la constitución, el régimen interno y el modo de elegirse las que las han de suceder, para resolver los problemas que enumera el Diario. Ante ellas comparecerán para ilustrarla, esos hombres doctos, esas representaciones y esos cuerpos consultivos, que tanto han preocupado en estos dias al colega". "Que los representantes de los brazos que puedan reunirse han de ser muy pocos y que no tendrian el influjo social que, traduciéndose en ascendiente políticos, les daba asiento en Cortes. Ah! Y iy qué le vamos a hacer si el respeto a un régimen preexistente de derecho nos impone esa realidad y ante ella no nos quedan más que dos caminos: o el de aceptarla, con 
todas sus consecuencias, o el absurdo de inaugurar el reinado de los Fueros, con el más grave de los contrafueros, el que se cometa contra la Majestad de las Cortes".

Para finalizar esa primera batería de artículos de opinión, el 24 de noviembre, la dirección del periódico carlista sostenía "con los textos de nuestros Fueros, que no quedábamos huérfanos de Constitución en el momento en que se derogase la Ley de 1839", indicando que "esas Cortes, aun con la composición anticuada que forzosamente habian de tener" representarian "tan bien o mejor a la sociedad de Navarra que a la española las de Madrid". También se criticaba la propuesta lanzada por Diario de Navarra porque "unos cuantos señores abogados, algunos de los cuales no tendrian la confianza del país, maniobrarian a su antojo a los representantes de los Ayuntamientos, de la Agricultura, la Industria, el Comercio, etc., etc., y serían de hecho los legisladores de Navarra. Esto no sería la Autonomia; esto sería un pastel".

Unos días después, el 28 de noviembre, El Pensamiento Navarro apuntalaba sus argumentos señalando hacía "la soberanía indiscutible de nuestras antiguas Cortes y su capacidad para determinar convenientemente cómo han de elegirse las que las sucedan para legislar sobre las necesidades de LA VIDA ACTUAL de Navarra”. Además, los carlistas denunciaban el déficit de legitimidad de la Ley de 16 de agosto de 1841 de acuerdo con los cánones constitucionales de la Constitución Histórica de Navarra: "El Diario sabe tan bien como nosotros, que el Pacto de 1841 no tiene la sanción de nuestras Cortes, y que intervinieron en su confección representantes elegidos ad hoc, que no gozaron de gran popularidad por su obra. Cuando está escrito en él puede modificarlo la Diputación de Navarra, de acuerdo con el estado, y en buena lógica imitando al Estado, que lo vulneró cuantas veces tuvo por conveniente, por su cuenta y riesgo. En ese pacto se legisló sobre la constitución y atribuciones de nuestra Corporación provincial. Ella y el Estado pueden proceder a modificarlas; pero ni una ni otro, ni juntos ni separados, tiene suficiente autoridad para legislar en Navarra. El modificar nuestras Leyes privativas es de la competencia exclusiva de las Cortes de Navarra, que pueden reunirse y que deben reunirse, después de la derogación tantas veces repetida porque son la única fuente de soberanía en esta tierra".

La perspectiva historicista y radicalmente defensora de los parámetros constitucionales de la Constitución Histórica de Navarra, desaparecida ochenta años atrás, de los editorialistas del órgano del jaimismo llegó a refutar a Arturo Campión, uno de los principales intelectuales del fuerismo navarro. Este había publicado un artículo en El Pueblo Navarro hacia finales de noviembre en el que decía que la Diputación debía reunir "dentro del más breve plazo posible, después de la derogación de la Ley de 25 de octubre de 1839, a la Junta de distritos o Merindades, en la forma que ha solido reunirlas cuando ha estimado oportuno administrar con su cooperación”. Dicha Junta, "oyendo a la Diputación foral y provincial, y a las personas doctas que estime oportuno, establecerá la organización, funcionamiento y manera de elegir las Cortes de Navarra, atemporándose a las circunstancias del País y a las posibilidades derivadas de estas"19.

19 José María Jimeno Jurio, Navarra y Vascongadas (1917-1919). Reivindicaciones autonómicas y Reintegración Foral, op. cit., pp. 239-240. 
El 5 de diciembre el periódico tradicionalista refutaba las tesis defendidas por Campión. El Pensamiento Navarro opinaba que "ni la Diputación, ni las Juntas de Distrito o Merindades, ni las personas doctas pueden, ni juntas ni separadas, acometer la labor importantísima de Derecho Constituyente, que el señor Campión estima necesario encomendarles". "Es evidente que ninguno de esos organismos tiene soberanía en Navarra hoy, y muchísimo menos el día en que se derogase la Ley de 1839. La Diputación no tiene ni la organización ni las funciones que asumió la Diputación del Reino: las suyas nacieron en el Pacto de 1841, que no es Ley en navarra, desde el momento en que le falta el requisito esencial de la sanción de nuestras Cortes. Las Juntas de distritos o merindades no son organismos forales ni extraforales: son comisiones circunstanciales que crea la práctica de la Administración para asesorar alguna rara vez; a las Diputaciones en determinadas materias. Cuando se ha citado a los representantes de los Ayuntamientos que las componen, han acudido en número muy escaso, y los que cumplieron con su deber no estimarán que les hacemos ningún menosprecio, si afirmamos que no son competentes para la altísima misión que se pretende encomendarles". Para el órgano jaimista, "solamente las Cortes Navarras, convocadas con arreglo a Fuero, son soberanas para decidir cómo han de elegirse y funcionar las que las hayan de suceder. Este es el único procedimiento posible, dentro de la legalidad navarra, que se inicia en el momento de la derogación de la Ley de 1839; y si bien es cierto que tiene imperfecciones orgánicas y dificultades en su ejecución, unas y otras están superadas, y con mucho, con las que han de ofrecen todas las demás fórmulas que se han propuesto y que adolecen de un pecado original: la falta de soberania”.

El 15 de diciembre comenzaba a publicar El Pensamiento Navarro una serie de artículos titulados Momentos gravisimos. Ráfagas de Gloria, firmadas por un tal Fuerófilo, en los que se llevaba hasta las últimas consecuencias la defensa teórica de que debían de ser las Cortes estamentales navarras, articuladas a la manera del Antiguo Régimen, las que debian de reorganizar el autogobierno navarro tras la derogación de la Ley de 1839 como depositarias que eran de la soberanía navarra según lo dictaban los parámetros constitucionales de la Constitución Histórica de Navarra ${ }^{20}$. Hemos podido saber que tras dicho seudónimo de Fuerófilo se escondia el abogado Sebastián de Urisarri, experto en derecho local foral. En un artículo publicado en El Pensamiento Navarro el 17 de enero de 1919 por Ignacio Baleztena Ascárate, que ostentaba el cargo de Inspector de dicho periódico que le había conferido la Junta Regional Carlista del Reino de Navarra, se remarcaba que en la campaña en pro de la reintegración foral apoyada por aquel "entre otras distinguidas personalidades del Partido, ha tomado parte principal el ilustre navarro don Sebastián Urisarri, reconocido por todos, propios y extraños, como maestro en cuestiones forales de este Reino". Además, en los artículos de la serie Momentos gravisimos. Ráfagas de gloria publicados a partir de 19 de enero de 1919 no aparecería ya la firma de Fuerófilo, sino la del propio Urisarri. Con todo, según se deduce de un artículo de Gabino Martínez de 18 de enero en El Pensamiento Navarro, a pesar de ser nominado por

20 Sobre las características de las Cortes estamentales navarras y de todo el tejido institucional navarro anterior a 1839 puede consultarse Jesús María Usunáriz Garayoa, “Las instituciones del Reino de Navarra durante la Edad Moderna (1512-1808)", Revista Internacional de Estudios Vascos, 46-2, 2001, pp. 685-744. 
los carlistas para formar parte de la Ponencia designada el día 4 de enero por la Diputación (finalmente compuesta por Lorenzo Oroz, Pedro Uranga, Félix Amorena y Joaquín Beúnza) para señalar "las normas del programa o plan de trabajo" para que sirviera de base para la actuación de la ponencia o comisión a que se refería el apartado segundo de la fórmula de reintegración foral aprobada, como veremos, en la Asamblea del 30 de diciembre, Urisarri fue dejado de lado por la Diputación, que prefirió a otros expertos.

En el primero de sus artículos Fuerófilo elogió "la inmensa bondad y perfección" de las Cortes estamentales navarras por su carácter orgánico y afirmaba que la restauración de las mismas era el objetivo por el que trabajaban "los buenos navarros". A su juicio, "pueden y deben" resurgir las Cortes navarras tal y como existian en 1829 "porque es de justicia fundamental, histórica y actual, su más pronta restauración, si se ha de salvar nuestra tierra querida de una horrible lepra naturalista, que Dios quiera que no logre roer entrañas que parece han renegado de su sangre y de su alma navarras".

El segundo artículo de Fuerófilo, del día 16 de diciembre, subrayaba la importancia de restaurar las antiguas Cortes. En el tercer artículo, publicado el día 20 de diciembre, Fuerófilo decía que urgía que la Diputación nombrase dos sindicos en esos momentos en que se debatía la reintegración foral. Proponía que se podian reunir las antiguas Cortes porque "existe el Brazo eclesiástico" con el obispo de Tudela, el deán de Tudela y el prior de Roncesvalles, porque "no serán pocas las casas nobles de Navarra, que aún conservarán su derecho de asiento en las Cortes" y porque "muy conocido es el número de los pueblos de Navarra que tienen también derecho a enviar sus diputados a las Cortes". Los síndicos nombrados elaborarian la lista de los representantes de los tres estamentos. En el artículo se planteaba "que una vez que estas Cortes se reúnan dicten una Ley en la que se disponga la organización que hayan de tener las Cortes de Navarra en lo sucesivo; y que una vez promulgada dicha Ley, que queden disueltas las primeras Cortes y que se convoquen inmediatamente otras, con la organización que las primeras hayan establecido por la ley". Tras la constitución de estas segundas Cortes, estas deberian "confeccionar una Ley fundamental en que se fijen las relaciones, derechos y obligaciones que hayan de mediar entre el Estado foral de Navarra y el Estado central de España, en todos los órdenes de Gobierno y administración y de las atribuciones y prerrogativas de las Cortes de Navarra, de la Diputación foral y de los ayuntamientos". Esas segundas Cortes designarian una Diputación permanente foral con las atribuciones señaladas por las Cortes.

Antes de la celebración de la Asamblea, el 29 de diciembre, Fuerófilo publicaría otro artículo de la serie en el que calificaba a las leyes de 1839 y 1841 como contrafueros y mencionaba la necesidad de denunciarlas como tales por parte de la Diputación.

Los argumentos de Fuerófilo fueron asumidos por los sectores reintegracionistas más radicales. En una hoja firmada por la Junta Gestora de la Juventud Pro-Navarra (formada por Ignacio Baleztena, Miguel Serdeño, Fernando Arvizu, Joaquin Fuentes, Félix Rubio y Jesús de Aranzadi) que fue reproducida por Diario de Navarra el 24 de diciembre, y que llamaba a la participación en un mitin en pro de la reintegración foral el día 29, la víspera de la Asamblea, aunque no se constata ninguna concreción sobre la implementación de aquella, en el alegato final se decia: “¡Vivan nuestros sagrados fueros! ¡Vivan nuestras Cortes propias!". 
Hay que decir que las tesis de Fuerófilo eran una adaptación a Navarra de la postura defendida por los carlistas en el Acta de Loredán de 1897 en la que se defendia la reintegración foral para Navarra y Vascongadas y para los antiguos reinos de la corona de Aragón. Como es sabido, en dicha acta se defendía la restauración de unas Cortes orgánicas “á la usanza española, no británica, ni francesa" como "libre y verdadera representación de todas las fuerzas sociales", convocadas "para asuntos previamente determinados" y mediante la elección de "procuradores idóneos".

\section{LA VIRTUALIDAD REAL DE LOS PLANTEAMIENTOS ANTERIORES EN LA ASAMBLEA DE 30 DE DICIEMBRE DE 1918 Y EL PROCESO POSTERIOR INMEDIATO.}

Las propuestas defendidas por los carlistas más radicalmente fueristas y defensores de la ortodoxia foralista desde El Pensamiento Navarro relativas a la manera según la cual debía de implementarse le reintegración foral chocaron con los planteamientos esgrimidos desde Diario de Navarra. Este último periódico abogó por una asamblea representativa de indole corporativa de nuevo cuño convocada por la Diputación y controlada por las élites, rechazando de plano las instituciones desaparecidas ochenta años atrás.

Las argumentaciones de Diario de Navarra fueron acompañadas de continuos llamamientos, sobre todo a los tradicionalistas, contra la proximidad del peligro bolchevique y sobre la eventualidad de que las reivindicaciones autonomistas actuaran como elemento facilitador de la revolución en el contexto crítico en el que entonces estaba desenvolviéndose España. De esta forma, el 9 de noviembre recogió una nota de la Junta Suprema del Partido Tradicionalista llamando a la colaboración con "las fuerzas politicas que proclamando la necesidad del mantenimiento del interés nacional, se hallen dispuestas a colaborar en la defensa de los principios religiosos, espirituales y de clase que conduzcan al reconocimiento de las autarquías regionales, dentro de la unidad de la patria y solución de los problemas sociales bajo la base de la propiedad individual y colectiva, siempre acatando las doctrinas de la Iglesia".

Asimismo, el día 15 de noviembre, y en relación con la petición del PNV de derogación de la ley de 1839, Diario de Navarra añadía a artículos anteriores que incidian que el único interlocutor de Navarra era su Diputación, que "cuando Navarra tenga algo que pedir lo pedirá ella misma" y juzgaba que había "llegado el momento en que Navarra debe pedir aquello a que Navarra tenga derecho, lo que sea su derecho, lo que necesite para desarrollar su vida espiritual y social". Seguidamente se expresaba largamente sobre el peligro bolchevique y señalaba que los problemas regionales se abordarian por unas Cortes constituyentes ante las cuales sería necesario llevar por parte de Navarra "una idea común, un pensamiento determinado, un programa de aspiraciones colectivas". El periódico conservador subrayaba que era necesario determinar por parte de Navarra "para ir a negociar" "determinar cuál es el objeto del negocio", "saber primero de una manera concreta, de una manera precisa, de una manera determinada, detallada y clara, qué es lo que se va a pedir" y determinar quién debía "de determinar qué es lo que Navarra va a pedir". Para Diario de Navarra los navarros debía ponerse de acuerdo y tanto Navarra como la Diputación debian irse preparando "para tan importante empresa". 
E1 20 de noviembre de 1918 desde Diario de Navarra en un artículo publicado en la sección titulada "De interés para Navarra", seguramente escrito por Raimundo García, el director del periódico conocido por sus seudónimos de Ameztia y Garcilaso, se respondía a El Pensamiento Navarro sugiriendo que la Diputación debía convocar a los diputados y a los hombres doctos del país y a los representantes de los municipios y de todos los organismos "que representen intelectualidad, capital, agricultura, etc" para consultarles de cara a "iniciar seriamente la obra que ha de llevarnos a la afirmación y recuperación de nuestros derechos". El periódico conservador creía que "en esa Asamblea magna, para asistir a la cual deben venir delegados de los Ayuntamientos elegidos por ellos libremente, se debe designar una comisión de letrados y de economistas que estudien y propongan un programa completo de reivindicaciones". Además de apelar a la Diputación para tratar del asunto porque este no permitía dilación, Diario de Navarra afirmaba su compromiso con la defensa de "las bases de nuestra Constitución futura, de nuestras demandas al Estado" cuando fueran aprobadas por "esa comisión o junta o ponencia de hombres doctos de todas las tendencias" "y las apruebe Navarra, sea cualquiera el acuerdo, sea cual sea la voluntad de Navarra".

Al día siguiente, el 21 de noviembre, en otro artículo en la misma sección, tras comentarse el acuerdo del ayuntamiento de Pamplona por el que se pedia la reintegración foral, se ahondaba en la misma idea expresada en el párrafo anterior y se añadía que el punto de partida para la mejora del autogobierno navarra debía ser la Ley de 16 de agosto de 1841. Diario de Navarra sostenía que "para concretar, para enumerar nuestras aspiraciones, es indispensable estudiar con método, discutir con sabiduría y con orden, y resolver de común acuerdo todos los navarros. La Ley del 41 es hoy nuestra Constitución, nuestro pacto con el Estado. Ahora queremos tener otra Constitución, otro pacto. ¡Pues hemos de acordarlo nosotros antes, para llevárselo hecho a la otra parte y poder decirle: Esto y esto y esto pedimos!". Asimismo, se apuntaba que "nuestras excitaciones a la Excelentísima Diputación van encaminadas a conseguir que cuanto antes se empiece a trabajar en la redacción de ese índice de la reintegración foral a que aspiramos" "y la redacción de ese indice, por ser una labor muy seria, debe hacerse con el mayor cuidado, sin precipitaciones; pero sin dejar un día en blanco porque los acontecimientos caminan muy deprisa". El periódico explicitaba que "el encargo de trazar el plano de nuestra restauración foral" la debian de hacer "hombres doctos".

Un día más tarde, el 22 de noviembre, Diario de Navarra replicaba a una carta del nacionalista Manuel de Aranzadi publicada en el número del día y a la que ya se ha hecho alusión más arriba. Tras criticar la supeditación a Vizcaya que representaba el hecho de haber solicitado el grupo nacionalista en exclusiva en las Cortes la derogación de la Ley de 1839, aquel periódico recordaba que tras la derogación de dicha Ley hacía "falta al día siguiente un régimen, un estado legal, una autoridad que asuma facultades y las ejercite" y que "esto es tarea difícil, cuestión compleja, cuestión gravísima, mucho más complicada para Navarra que para las otras regiones vascas". De esta forma, Diario de Navarra citaba unos párrafos de una charla de Arturo Campión en el Centro Vasco de Pamplona del 6 de enero de 1914 en la que decía que el programa del partido nacionalista de derogación de la ley de 1839 era fácil de cumplir en relación con Alava, Guipúzcoa y Vizcaya, pero “imposible en cuanto atañe a Navarra” porque 
"si los elementos generadores y constitutivos de las Juntas Generales subsisten" en aquellos tres territorios, "los de las Cortes de Navarra perecieron" al haber desaparecido los miembros del brazo eclesiástico y los dueños de los palacios de cabo de armería y por suscitarse dudas en cuanto a la conveniencia de resurrección de los antiguos estamentos por cuanto miembros de la nobleza y del clero servian a Castilla. Por todo ello, Campión finalizaba que habría que contentarse "con el firme propósito de restaurar en la forma posible el poder legislativo nabarro". En base a todo ello, Diario de Navarra concluía el artículo diciendo:

"No hablemos, pues, de nuestras antiguas Cortes, porque esas, tal como estaban constituídas, dificilmente encontrarán hoy un solo defensor en Navarra.

Hablemos, sí, de la función legislativa que surge realmente al revocarse la ley de 1839 y 1841. ¿No hemos de pensar, siquiera en líneas generales, fundamentales, quién ha de asumir ese poder legislativo, y cómo ha de ser designado o elegido? ¿Es que vamos a empezar a disputar entre nosotros al día siguiente? Y aun suponiendo que eso le sea indiferente a Navarra y se acepte en definitiva cualquiera forma de poder legislativo ¿estamos preparados para legislar? Porque al derogarse la ley de 1841 es claro que todas las leyes posteriores, incluso la Constitución del Estado, se derrumban por lo que a Navarra se refiere; y hay que pensar en establecer los derechos politicos de los navarros con más o menos libertades; y hay que reorganizar Ayuntamientos y concejos según leyes propias; y hay que pensar en el régimen aduanero; y en la reorganización de tribunales nuestros; y en la anulación del servicio militar o en la determinación de la forma en que esto ha de prestarse, porque todo esto y mil cosas más implica la derogación de las leyes de 1839 y 1841 ya que esa derogación o es una burla o es la reintegración de nuestro poder legislativo pleno y sin trabas".

Por último, Diario de Navarra pedía a Aranzadi que explicitase las consecuencias de la derogación, a la par que negaba que en dicho periódico fueran "unos fósiles adheridos a la ley de 1841". Para dicho periódico esta ley podía "revocarse mañana", si bien pedía "que Navarra conozca las consecuencias de la transformación y acuerde, en lo posible, la forma de sostenerla y desarrollarla".

El 23 de noviembre Diario de Navarra respondía en un artículo a otro de El Pensamiento Navarro sobre las Cortes de Navarra que surgirian tras la derogación de la ley de 1839, subrayando, con Campión, la imposibilidad de que se restauraran en 1918. Diario de Navarra admitía que se podría resucitar el brazo popular con representantes municipales, pero expresaba sus dudas en relación con los demás estamentos, así como por el apoyo que las cortes estamentales recibirian de republicanos federales y socialistas. A la par, repetía la conveniencia de "meditación, orden, unidad, demandas concretas y sabiamente articuladas y formuladas".

Posteriormente Diario de Navarra no volvió a opinar acerca de la cuestión. Con todo, sus tesis triunfaron al ser las finalmente asumidas por la Diputación y por la Asamblea que finalmente se celebraría el 30 de diciembre.

E1 18 de diciembre dicho periódico publicaba una reproducción de la nota oficiosa transmitida por la Diputación sobre el acuerdo tomado por la misma el día 16 sobre la derogación de la ley de 1839 y la reintegración foral. Se acordó 
convocar para el 30 "una Asamblea magna constituída por la Representación en Cortes, Consejo Administrativo de Navarra y los ayuntamientos de la provincia, representados estos por uno o dos vocales de los mismos, a fin de tratar de si debe de pedir la Diputación a los Poderes públicos la derogación de la ley de 25 de Octubre de 1839, una vez considerada esta, por la Asamblea, en su aspecto social, político, económico y jurídico". El acuerdo se tomó tras haberse debatido acerca tres mociones sobre la cuestión: una presentada por Usechi (que fue apoyada asimismo por los también liberales Baztán, Badarán y Guelbenzu); otra del carlista Sanz y del integrista Juanmartiñena; y otra del jaimista Martínez Alsúa. La moción de Usechi pedía "una convocatoria y reunión de Ayuntamientos navarros (por medio de representantes de los mismos) asistidos del Consejo Administrativo y de navarros doctos, que manifiesten sus deseos en asunto tan importante y trascendental como es el de la reintegración foral". Esta moción planteaba que en la asamblea comparecieran como expertos Amorena, Beúnza, Oroz, Uranga y Campión para manifestar "los aspectos del problema en sus fases histórica, social, política, económica y jurídica". La moción de Sanz y Juanmartiñena partía de la opinión de que la petición de la "absoluta reintegración" de los fueros era una decisión que debía "ser tomada por una Corporación dotada de autoridad competente y esta Corporación no puede ser otra sino una asamblea constituyente, que represente a la unión de todo el pueblo navarro". Añadian que la Diputación de entonces, "así como todas las que la han precedido desde el año 1841" eran "incompetentes para tratar de este gran asunto". Entendian que debian reunirse "las representaciones de todo el pueblo". La moción de Francisco Martinez Alsúa en sus dos puntos primeros copiaba literalmente el acuerdo del ayuntamiento de Pamplona; en el punto tercero pedia solicitar a los diputados a Cortes por Navarra que plantearan en el Parlamento "la reintegración foral para Navarra, pidiendo la derogación de la Ley de 25 de octubre de 1839"; y en el punto cuarto pedia a esos diputados a Cortes actuar al unísono con los diputados de Vascongadas.

Ese acuerdo fue duramente criticado por El Pensamiento Navarro. El 21 de diciembre un entrefilete en negrita en dicho periódico pedía a los representantes de los ayuntamientos que fueran a la asamblea convocada por la Diputación para que preguntasen a la Diputación: “¿qué ley navarra, o cuál de las que están vigentes en el Estado español, da facultades a esa Asamblea para decidir de la vida o de la muerte de nuestros Fueros venerandos? ¿qué precepto navarro o del Derecho público moderno, autoriza a esa Asamblea para erigirse en dictadora de Navarra, burlando la voluntad de la inmensa mayoría de los pueblos y llamándolos, de rechazo, imbéciles o menores de edad que no saben lo que piden?". Se pedía que "procuren los pueblos enviar representantes que formulen con entereza estas preguntas" para que se acordara la ratificación de los deseos expuestos por los 212 ayuntamientos que habian pedido la reintegración foral durante las semanas anteriores, respondiendo a los requerimientos del ayuntamiento pamplonés. El filete se reprodujo los siguientes dias, acompañado de artículos como uno de del 24 en el que se discutía la autoridad de la Asamblea convocada. 


\section{LA POSTURA TOMADA POR LA ASAMBLEA DE 30 DE DICIEMBRE.}

Por último, en la Asamblea celebrada en el Palacio de la Diputación el 30 de diciembre de 1918, se acordó aprobar por aclamación la proposición siguiente: “1) Que siendo aspiración constante de Navarra la reintegración de su régimen foral y habiendo reconocido el Gobierno recientemente la conveniencia de otorgar una organización autonómica a las diversas regiones, considera la Asamblea llegada la oportunidad de que partiendo del régimen juridico actual, haga presente la Diputación al Gobierno que Navarra reitera una vez más sus propósitos de restaurar sin quebranto de la unidad de España, la integridad de sus facultades forales, con derogación de todas las leyes y disposiciones que a ellas se opongan, manteniendo las especialidades características de este antiguo Reino adaptadas a las actuales necesidades y conveniencias de Navarra y armonizadas con las facultades del Estado español en las materias propias de este; 2) Que la Diputación designe una Comisión que estudie y proponga concretamente las bases del nuevo régimen". Esa proposición finalmente aprobada fue presentada tras el saludo de la presidencia a la asamblea ${ }^{21}$ y habia sido firmada por 25 cargos, 8 carlistas y 17 liberales. Los carlistas eran Cesáreo Sanz Escartín (senador), Tomás Dominguez Arévalo, Joaquín Llorens, Victor Pradera (dipuados a Cortes) y Joaquín Beunza, Ramón Lasantas, Blas Morte y Juan Santesteban (exdiputados forales). Los liberales era Valentín Gayarre, el vizconde de Valderro (senadores), el conde del Vado, Celedonio Leyún y José María Méndez Vigo (diputados a Cortes) y los exdiputados forales Félix Amorena, J. M. Astiz, Severino Blanco, Domingo Elizondo, Dámaso Escudero, Joaquín Garjón, Joaquín Gastón, Rafael Gaztelu, Máximo Goizueta, Demetrio Martínez Azagra, Lorenzo Oroz y Pedro Uranga ${ }^{22}$.

Como puede verse, la resolución tomada en dicha asamblea era de una calculada ambigüedad: no se rechazaba la reintegración foral ni se dejaba de reclamar la derogación de las leyes que atentaran contra las facultades forales, pero entre estas no se mencionaba las leyes de 1839 y de 1841, cuya derogación, al ser la segunda producto de la primera, habia sido explícitamente solicitada por los ayuntamientos. Por otra parte, se subrayaba la necesidad de mantenimiento de la unidad de España y de armonizar las reivindicaciones autonómicas con las conveniencias de Navarra y las facultades del Estado. También se hablaba que la Diputación elegiría una comisión que abordara el tema. Como se ha dicho más arriba, los cuatro expertos foralistas a los que recurrió la Diputación eran firmantes de la propuesta presentada a la Asamblea del 30 de diciembre.

Respecto a los contenidos tratados en la mencionada Asamblea nos centraremos exclusivamente en los relacionados con la forma de implementación de la reintegración foral. El conservador Pedro Uranga, exdiputado foral y exsecretario de la Diputación estrechamente vinculado a la élite ligada a Diario de Navarra, defendió la propuesta como adecuada a lo que se había solicitado a la Diputación $^{23}$. El carlista, y exdiputado foral, Joaquín Beunza defendió que la

21 La reintegración foral de Navarra. Acta de la Asamblea celebrada en el Palacio Provincial el dia 30 de diciembre de 1918, Pamplona, Imprenta Provincial, 1919, p. 11.

22 José María Jimeno Jurio, Navarra y Vascongadas (1917-1919). Reivindicaciones autonómicas y Reintegración Foral, op. cit., p. 295.

23 La reintegración foral de Navarra. Acta de la Asamblea celebrada en el Palacio Provincial el dia 30 de diciembre de 1918, op. cit., pp. 15-19. 
reintegración foral plena debía de hacerse dentro del Estado español y dentro de la unidad nacional. Defendió que la Comisión fuera nombrada por la Diputación y no por la Asamblea porque aquella podía "hacerlo con más calma y reflexión" e hizo una analogía en la composición de dicha comisión respecto a la que tenían las Cortes, dando cabida al clero, a la nobleza y a las "Sociedades económicas de Amigos del País, Asociaciones de viticultores, de ganaderos, obreros, Cámara de Comercio y de la Industria, Colegios de Abogados, las Cajas Rurales, etc."24. Los nacionalistas Cunchillos, concejal en Pamplona, y Aranzadi, diputado a Cortes, dijeron que en la propuesta no se mencionaba la derogación de la ley de 1839, añadiendo el segundo de ellos que la fórmula que no solicite la derogación de esa ley "en un sentido o en otro es un pastel". Recalcó que "en cuantas ocasiones Navarra, puesta en pie y sacudiendo su apatía en estas materias se ha propuesto afrontar el problema de su reintegración foral, se ha notado la falta de fijeza, la falta de criterio definido, la falta de una norma positiva para resolverlo". No obstante, aparte de pedir la derogación de la ley de 1839 Aranzadi no aportó ninguna vía de cómo gestionar la situación ulterior a dicha derogación. Solamente propuso como propuesta alternativa la que propuso Francisco Martínez Alsúa ante la Diputación y que se correspondía con la que aprobó el ayuntamiento de Pamplona con el añadido de actuar conjuntamente con las Provincias Vascongadas ${ }^{25}$.

Quien más duramente criticó las propuestas de implementación de la reintegración foral plena a través de la resurrección de las Cortes navarras extintas ochenta años atrás fue el tradicionalista y diputado a Cortes Víctor Pradera. Subrayó la antiforalidad de la solicitud hecha por el ayuntamiento de Pamplona ratificada por la inmensa mayoría de los ayuntamientos navarros porque, según él, la ley de 1839 "era una ley de confirmación, falsa, pero de confirmación de los fueros" en cuanto que el 6 de septiembre de 1837 "se había dictado la ley fundamental de derogación de los fueros", de forma que si se derogaba la ley de 1839, permanecía la ley de 1837 "que es la que fundamentalmente es derogatoria de los fueros". Aunque se manifestó repetidamente a favor de la reintegración foral, indicó que "la instauración de la reintegración foral sería para Navarra un gravísimo daño", sobre todo por sus repercusiones económicas. Por otra parte, afirmó que "las Cortes de Navarra no se pueden constituir hoy, sin ser una caricatura despreciable de aquella gloriosas" porque del brazo eclesiástico "no quedan más que dos representantes" y porque, en función de la capacidad de veto de los estamentos, no se podía poner la capacidad legislativa en tan pocas personas. Tampoco habria suficientes miembros para el brazo nobiliario puesto que solamente podría presentarse un "muy escaso número" de representantes, que en muchos casos dependian del Estado español. Tampoco el brazo popular "por la marcha de los tiempos y porque los principios de las Cortes no tuvieron tiempo de desarrollarse en Navarra", "gozaría su plena representación" al faltar numerosos municipios. También existía el problema del sistema de elección porque las Cortes navarras se regian por el sufragio orgánico y en el momento actual "el medio de elección es el sufragio universal", lo que daría lugar a protestas ante el hecho de no estar de acuerdo con dicho medio de elección. Por último, Pradera remarcó las diferencias

\footnotetext{
24 Ibid., pp. 19-24.

25 Ibid., pp. 25-36.
} 
entre la vida foral de Navarra y la de las Vascongadas y afirmó que "Navarra tiene sus características especiales y no tiene por qué ir a rastras de nadie en esta cuestión"26.

Por lo tanto, nadie defendió en la Asamblea las posturas del sector más radicalmente fuerista del carlismo y que habían sido defendidas desde las páginas de El Pensamiento Navarro. Además, personalidades tradicionalistas como Beúnza y Pradera se desentendieron absolutamente de ellas, llegando el segundo de ellos a criticarlas abiertamente. Y los nacionalistas Cunchillos y Aranzadi fueron incapaces de hilar un discurso que describiera sobre cómo debía de ponerse en práctica la reintegración foral a partir de la derogación de la ley de 1839 de una forma moderna y seductora para el sector de la ciudadanía que apoyara un mayor autogobierno y no quisiera regresar a un escenario propio del Antiguo Régimen.

El acuerdo tomado por la Asamblea finalmente no desembocó en nada concreto. El 23 de enero de 1919 la prensa publicaba una nota oficiosa de la Diputación en la que se notificaba que se había recibido el escrito de los comisionados Lorenzo Oroz, Pedro Uranga, Félix Amorena y Joaquín Beunza "señalando las normas del programa o plan de trabajo" que se les había encomendado "para que sirviera de base para la actuación de la ponencia o comisión a que se refiere el apartado segundo de la fórmula de reintegración foral aprobada en la Asamblea". El día 28 los periódicos navarros recogían otra nota oficiosa de la Diputación sobre la composición de la comisión por la reintegración foral, una composición teñida del corporativismo mellista y que hacia un leve guiño a la estructura estamental del antiguo legislativo navarro. Estaria integrada por seis representantes de los cabildos de Pamplona, Roncesvalles y Tudela y párrocos de Navarra designados por los obispos; los representantes en Cortes de Navarra; el Consejo Administrativo de Navarra; cuatro representantes como máximo de los ayuntamientos de cada distrito elegidos por los mismos en Juntas de distrito; los alcaldes de Pamplona, Tudela, Estella, Tafalla, Aoiz; un representante de la Comisión de Monumentos Históricos y Artísticos de Navarra; cuatro socios de la Cámara Oficial de Comercio e Industria de Navarra; dos abogados elegidos por el Colegio de Abogados de Pamplona; dos médicos nombrados por la Asociación Médica; dos Farmaceúticos, dos notarios; cinco ingenieros; un arquitecto; dos representantes de la Asociación de Secretarios Municipales; dos de la de Veterinarios; tres de la Federación Católico Social; uno de la Asociación de Ganaderos; uno de la Asociación de Viticultores; uno de la Caja de seguros contra el pedrisco; uno de la Sociedad Económica de Amigos del País de Tudela; dos del partido carlista; dos del integrista; dos del liberal; dos del republicano; dos del nacionalista; dos del maurista; y dos del socialista. Se reunirian el 17 de febrero. En esa reunión acordaron simplemente estructurarse en comisiones que trabajarian sobre parcelas concretas. Según la prensa del 27 de febrero, aparte de una Comisión Permanente, habría trece comisiones sectoriales cuyos trabajos no dieron ningún fruto. El Pensamiento Navarro interpretaría el 8 de abril de 1919 que habían triunfado los antifueristas, contemplando la labor de las comsiones como fraude y como maniobra dilatoria.

26 Ibid., pp. 36-52. 


\section{LA RESISTENCIA DEL SECTOR DEL CARLISMO MÁS RADICALMENTE FUERISTA A ABANDONAR SUS TESIS.}

Tras la Asamblea, Urisarri continuaría defendiendo sus tesis con más artículos de la serie mencionada. El 19 de enero de 1919 se centró en las Cortes que debían surgir con la reintegración foral y su organización y composición. A su juicio, las Cortes convocadas a la manera antigua ampliarian probablemente "el número de Diputados en el brazo de las Universidades, dando derecho de elección, a todos los Ayuntamientos, de un número determinado de diputados por cada Merindad". No obstante, la elección no sería mediante sufragio universal, del que el firmante era feroz enemigo, sino "intermediada por medio de Ayuntamientos y veintena, oncena, etc., evitando así esos procedimientos de corrupción electoral que llegan a envilecer de modo escandaloso a los pobres electores ignorantes o malvados, vendiendo sus votos en subasta a quien más dé. Esto es horrible, y fatídico peldaño por donde baja la vileza, sube la soberbia, y se desprestigian, de manera denigrante y odiosa, el elector, el sistema electoral y la jerarquía del cargo". Ese sistema indirecto de elección de "diputados de los pueblos para las Cortes navarras" conllevaria "apreciadísimas ventajas de moralidad en la elección, y de mayores en alto grado probabilidades de acierto para elección de diputado aptísimo y prestigioso". Con todo, en ese mismo brazo popular no haría solamente representantes municipales sino que se daría entrada asimismo "a diputados elegidos por las diversas Asociaciones o gremios profesional de Artes o Oficios, dadas la importancia que hoy tienen, y la consideración que se merecen estas agrupaciones en el orden social en su relación con el político". En la composición de las nuevas Cortes navarras diseñadas por las Cortes al viejo estilo estas también modificarian la estructura de los demás estamentos. Así, por ejemplo, en el estamento nobiliar se daria entrada "no solo a la aristocracia de la cuna, sino también a la de la ciencia, de las artes, del comercio, industria fabril, trabajo, banca, etc.”. Y entre los integrantes del brazo eclesiástico estarian también "ilustres clérigos navarros, sabios eminentes en filosofia moral, en derecho natural, en ciencia sociológica". Urisarri negaba la posibilidad que hubiera algún "buen navarro" que se atreviera "a sostener que la reintegración foral de Navarra se ha de hacer, y que se han de abrir sus Cortes sin el Brazo Eclesiástico" por ser este "tan esencial en las Cortes, que sin él se quedarían estas mancas sin la más segura orientación para resolver todos los puntos de legislación; pues sin él bogaría esta como nave sin faro seguro entre los horribles escollos del perverso y corruptor naturalismo". Todo el enfoque de Urisarri seguía las pautas expresadas por los dirigentes carlistas que en 1897 redactaron la ya mencionada Acta de Loredán.

En conformidad con su apego a la ortodoxia tradicionalista, en su última aportación, el 12 de febrero de 1919, Urisarri atacó el parlamentarismo y el sufragio universal. Según él, "lo que el pueblo quiere, lo que todos queremos, es buenas leyes hechas en Cortes secretas, en que la verborrea no ahogue a la ciencia". Las Cortes navarras no podian ser elegidas mediante sufragio universal por ser este "engendro de un dislocador y antisocial individualismo" y por ser la organización tradicional "maravillosa". Además de repetir que cualquier modificación la debían hacer las Cortes navarras, insistía en la presencia del brazo eclesiástico porque no se podian cerrar "al Clero las puertas de las Cortes navarras". Por último, se criticaba la asamblea que se iba a celebrar ese mes porque "en ella parece que se viene a proponer no la reintegración completa foral 
de Navarra, objetivo único y exclusivo de esta patriótica campaña fuerista, sino una especie de Constitución nueva foral. Si ello es así, claro parece un enorme contradictorio entre reintegrar nuestro tradicional régimen foral, y el sustituirlo con otro nuevo adoptado a las exigencias y necesidades de los tiempos". En esta linea, expresaba su "asombro y honda pena" por los contenidos de algunas intervenciones en el Asamblea del 30 de diciembre "porque en tales frases y conceptos hay errores tales, que pueden inducir a menosprecio de venerandas instituciones navarras y a conceptuar gravosa la reintegración foral" y alertaba contra "los neofueristas o seudofueristas".

Por su parte, según una información publicada en El Pensamiento Navarro el 3 de febrero de 1919, su director, Jesús Etayo se había manifestado el día anterior en una conferencia como favorable a la restauración, aunque modificados, de las Cortes, Diputación, Camara de Comptos, Real Corte, Consejo Supremo, Virreinato.

Esas tesis de Etayo no eran nuevas. En una conferencia dada a la Juventud Carlista de Pamplona en marzo de 1916, según El Pensamiento Navarro de 4 de aquel mes, "se mostró partidario de la reintegración foral, pero aclaró que, si triunfaran, no querrian resucitar las leyes e instituciones antiguas: querrian Cortes no formadas por brazos (...), sino en las que estuvieran representados todos los pueblos y las clases sociales navarras"27.

No obstante, aquella información suministrada por el órgano del jaimismo el 3 de febrero de 1919 resumía excesivamente los contenidos de la charla de Etayo. Al ser publicada posteriormente en su integridad, podemos ver que incorporaba matices de interés.

En su disertación Etayo comenzaba apuntando que las circunstancias habían "cambiado radicalmente" en relación con la reintegración foral. A su juicio, esas circunstancias alteradas eran "tales que nunca, en nuestra alma de navarros, pudimos esperarlas. Antes la reintegración foral era solo un sueño dorado; nadie pensaba que pudiera llegar a ser una realidad. Confesémoslo: éramos fueristas, pero no teníamos fe, no teníamos esperanza. Bastaba para satisfacer nuestra conciencia afirmar el deseo de la reintegración foral y precisar bien el alcance de nuestro deseo. Por eso nuestra labor solo tuvo de positivo la afirmación foral y tuvo de negativo la contradicción de los que honradamente reputábamos y reputamos extravios nacionalistas. Ahora la acción magnífica, admirable de Cataluña, de todo el pueblo catalán -a mí esto me parece indudable- nos ha infundido, no más conciencia foral, pero sí más fe. Mirando a Cataluña he comprendido yo cuán bueno, cuán eficaz es para un pueblo fiar en sí mismo y me he dicho: esto es lo que debe pensar Navarra. Que no es ya un sueño dorado, que no será una nostalgia, la plenitud de su vida foral, sino que puede obtenerla, que ha de obtenerla, que la obtendrá -no lo dudéis, si sois navarroscon su voluntad, con su acción, solo con ellas, es decir que obtendrá de sí misma"28.

27 Ángel García-Sanz Marcotegui, El fuerismo constitucional y la Diputación de Navarra (18411923), Pamplona, Gobierno de Navarra, 2011, p. 130.

28 Jesús Etayo Zalduendo, La reintegración foral de Navarra. Conferencia en el Círculo Carlista, dada el día 31 de enero de 1919, Pamplona, Casa Editorial Huarte, 1919, pp. 3-4. 
Etayo recalcaba que "la hora presente es la de definir claramente nuestro pensamiento sobre la reintegración foral y también, y principalmente, la hora de actuar, la hora de movernos, de agitarnos, para lograr la resurrección de Navarra"29, así como que "la forma jurídica" para lograr la reintegración foral "es la derogación de la ley de 1839 y su secuela la de 1841, volviendo al estado de Derecho, salvo las intentonas constitucionales desde 1812 al 1837, subsistente hasta entonces"30.

No obstante, la reintegración foral debía ser adaptada a los tiempos y debía ser negociada con el Estado: como aquellos habian cambiado, "todas las variaciones que sean indispensables para mantener actualmente la vida de relación de Navarra y el Estado no ha de imponerlas unilateralmente el Estado sino que Navarra libremente ha de concertarlas con el Estado, ahora $y$ siempre" 31 . En su opinión, "la sustancia de la reintegración foral" consistía "en que Navarra recobre su libertad para regir todos sus asuntos interiores y, por tanto, reintegración foral habrá con cualesquiera instituciones que Navarra libremente y en pacto con el Estado se dé". Etayo era "partidario fervoroso de que, para lo futuro, se restauren, aunque deban ser modificados, los antiguos organismos. Que se restauren las Cortes para legislar, que se restaure, como poder ejecutivo, la Diputación del Reino que era una delegación de las Cortes; que se restaure la Cámara de Comptos para el examen de las cuentas del Reino; que se restauren los Alcaldes de Corte en los pueblos, el tribunal de la Real Corte y el Consejo Supremo para la administración de Justicia; que veamos aquí no Gobernadores caciquiles sino el antiguo virreinato con todo su prestigio, para representar al Rey de Navarra, que es el Rey de todas las Españas". "Es convenientísima, a mi juicio, para Navarra la restauración de esos organismos, porque ellos, más que otros inventados ahora, serán instrumentos adaptables a la vida foral de Navarra y ellos tendrán aquel prestigio, aquella autoridad que indudablemente poseen las cosas seculares" 32 .

Esa labor debía ser acometida, según Etayo, por la asamblea del 17 de enero de 1919 que, en primer lugar, debia aprobar la derogación de la ley de 1839. "Enseguida de hacer eso, y como consecuencia de ello, se plantean problemas que es necesario resolver: la adaptación de nuestras esencias forales a las realidades de los tiempos presentes y a la futura situación próxima de relación con el Estado que, de momento, nos es desconocida; el régimen transitorio entre el actual al que estamos sometidos y el futuro que ha de regular la vida de este antiguo Reino; la vida municipal, que es, evidentemente, materia de la mayor importancia; la SEGUNDA EDICIÓN, que naturalmente, ha de ser muy corregida, de los organismos tradicionales de administración y gobierno de Navarra con las correcciones necesarias en lo que se refiere a la forma de su constitución -porque ya era defectuosa cuando vivian y, además, han variado los hechos sociales que les servian de base- y otras correcciones también que ha de imponer, mientras subsista, el régimen del Estado, tan radicalmente distinto, con su monarquía y sus gobiernos constitucionales y con sus parlamentos generales, de aquel otro

\footnotetext{
29 Ibid., p. 5.

30 Ibid., p. 6.

31 Ibid., pp. 6-7.

32 Ibid., p. 7.
} 
régimen verdaderamente monárquico, sin cámaras legislativas generales ni tribunales supremos centrales, que convivió, desde el siglo XVI, con nuestro régimen de libertad y plenitud foral"33.

En otro artículo en El Pensamiento Navarro el 17 de febrero el mismo Etayo concretaba una cuestión importantísima no analizada en la conferencia anterior. En él señalaba que la Comisión por la reintegración foral que se iba a reunir ese día debía "ratificar la aspiración foral completa y encargar a una ponencia de pocas personas competentes y fueristas de verdad la redacción en plazo breve de la futura constitución navarra, cosas que puede hacer en media hora la Comisión".

De cualquier forma, queremos subrayar que si bien Etayo se alejaba de Urisarri en cuanto que no mencionaba la opción de resurrección de las Cortes estamentales para la implementación adecuada a los tiempos del nuevo estatus ligado a la derogación de la ley de 1839, hacia el final del párrafo anterior no dejaba de expresar que el aggiornamento que él apoyaba era un imperativo forzado por el Estado liberal constitucional, mientras este subsistiera, y que, en el fondo, la solución que él consideraba, como buen tradicionalista que era, totalmente auténtica era la relacionada con el contexto de la distribución de los poderes propia del Antiguo Régimen.

El 26 de abril de 1919 un artículo firmado con el seudónimo de Javier de Sada y titulado “¡Reintegración foral!” defendía, con alguna variación, las posturas de Urisarri. Las Cortes navarras que acometieran la reintegración foral debian de estar formadas por los tres estados; en el estamento de los pueblos debian estar "todos los de Navarra, haciéndose las elecciones por Ayuntamientos $\mathrm{y}$ veintenas por Merindades, conforme al procedimiento foral"; en el estado nobiliario "la nobleza bajo todos los puntos de vista social: de cuna, de ciencia, de artes, de industria"; y en el "estado eclesiástico a diputados de Arciprestazgos elegidos por los párrocos de los mismos”.

\section{EL ENFRENTAMIENTO ENTRE LOS DOS SECTORES DEL CARLISMO.}

Las posiciones defendidas antes y durante de la Asamblea de sectores antagónicos del carlismo se manifestaron claramente dias después. Tradicionalmente se ha interpretado que su oposición venía condicionada por su negativa o aquiescencia a pactar con los nacionalistas (de hecho, Pradera acusó a sus opositores en sus mismas filas de ser "jaimistas nacionalizantes"), pero como ha quedado claro en los apartados anteriores sus diferencias se cifraban asimismo en su grado de exigencia respecto a la derogación de las leyes de 1839 y 1841 y la manera de cómo implementar el escenario políticoinstitucional fruto de ese cambio legislativo en aras de la consecución de un mayor autogobierno. Mientras unos eran radicalmente favorables a que aquellas leyes fueran derogadas, los otros apostaban en el fondo por la conveniencia de la ley de 1841 en aras de la estabilidad institucional frente a la revolución y el separatismo; mientras unos apostaban por la ortodoxia historicista de los autores defensores de los cánones constitucionales marcados por la Constitución Histórica de Navarra propia de un contexto de Antiguo Régimen, los otros contemplaban como

33 Ibid., p. 11. 
imposible, por anacrónica, la resurrección de las viejas institucionales a la manera feudal. Esas posturas eran previas al inicio de la campaña reintegracionista. Ya el 26 de julio de 1917 Pradera, entrevistado en Diario de Navarra por Garcilaso, director del periódico, alertaba que la campaña obedecía a los intereses de los nacionalistas catalanes y vascos y que el momento, dada la situación de crisis que se vivía en España, no era en absoluto adecuado para el planteamiento de las reivindicaciones reintegracionistas

Con posterioridad a la asamblea, el 4 de enero de 1919 en un artículo en respuesta a otro de El Pensamiento Navarro, Diario de Navarra recalcó la contribución de un sector del carlismo al desenlace final de la reunión celebrada pocos dias antes al mencionar que "es cierto que tres carlistas, los señores don Cesáreo Sanz, don Víctor Pradera, y don Joaquín Beunza obtuvieron un señalado triunfo defendiendo la proposición presentada y aclamada por la insigne Asamblea". También decia que desde la misma prensa tradicionalista se señalaba que amigos y adversarios elogiaban la labor de esos tres "ilustres personajes carlistas", labor que fue "tan potente, tan unánime y tan clara, que podemos señalar la intervención de los jaimistas en la asamblea como un triunfo notable" para la causa del carlismo.

Quince días más tarde, el 19, Diario de Navarra hurgaba en la misma circunstancia que acreditaba la división interna jaimista al afirmar que habian oído "a varios carlistas de Pamplona, y de fuera de Pamplona, opiniones radicalmente opuestas a la sustentada" por el órgano oficial carlista, comprendiendo entonces que la campaña de El Pensamiento Navarro "se hacía por algunos jóvenes animosos, extremistas, apasionados ...Vamos por una especie de grupo spartacus del jaimismo". Diario de Navarra también señalaba que "luego se vio, ya públicamente, que el divorcio existía no solo respecto de las autoridades supremas y respecto de elementos que llamaremos viejos (...) del partido carlista, sino que existía además respecto de otros elementos jóvenes, también briosos". Para el periódico conservador, con Pradera "estuvieron y están muchos jaimistas navarros". Asimismo, añadía que la Junta Suprema de la Comunión Tradicionalista a través de su presidente, el navarro Cesáreo Sanz, había desautorizado la campaña "violenta e injusta" de El Pensamiento Navarro.

Ya el 2 de enero de 1919 Diario de Navarra había informado de una escisión en el carlismo llamada Acción Tradicionalista, partido del que el día 8 se publicaba su manifiesto. El 21 aquel periódico publicó una carta de dicha formación escindida en la que mostraban su apoyo a la derogación de la ley de 1839, pero rechazaban al grupo de El Pensamiento Navarro que había dinamizado la campaña por la reintegración foral. Asimismo, el 16 de marzo Acción Tradicionalista expresaba su apoyo a Pradera. El periódico conservador también informó repetidamente de las tensiones internas del jaimismo que derivarian en la ruptura de Mella.

Tras la escisión mellista, la animosidad se despertó a finales de mayo de 1919 incluso entre los tradicionalistas que habian participado de la solución acordada por la Asamblea del día 30 de diciembre. El 28 de mayo Diario de Navarra publicaba una carta de Víctor Pradera sobre la campaña contra él de $E l$ Pensamiento Navarro en la que decía que su propuesta en la Asamblea llevaba también las formas de Beunza y de Rodezno y, por tanto, "si yo soy centralista, esos señores, alma del neojaimismo que ha sido engendrado en las bases de un cesarismo sin ejemplo, son tan centralistas como yo. ¡Y el jaimismo tiene en ellos 
sus más fuertes columnas!". Al mismo tiempo, Pradera acusaba a los jaimistas reintegracionistas señalando que su "antiguo partido se intoxicó de un nacionalismo que no tenía siquiera la virtud de la franqueza". El día 30 en el mismo periódico Pradera criticaba a Beunza de no haber ejercido su influencia en el periódico tradicionalista en relación con la campaña contra Pradera y de mantener una postura quietista.

\section{A MODO DE CONCLUSIÓN. MEMORIA Y DESMEMORIA EN EL DEBATE REINTEGRACIONISTA DE 1918.}

Los posicionamientos sobre cómo implementar la reintegración foral del sector reintegracionista más radical del carlismo tienen un profundo aroma historicista. Los argumentos manejados por Urisarri parten del axioma fundamental de la Constitución Histórica de Navarra a lo largo del Antiguo Régimen: la necesidad de la convocatoria de las Cortes estamentales navarras para refrendar los cambios politicojurídicoinstitucionales que supusieran una transformación de aquella. En un artículo anterior ${ }^{34}$ ya vimos cómo ese axioma fue recordado con ocasión de la constitución de Bayona y de la Constitución de 1812. En el caso de esta última la reclamación fue totalmente en vano por la imposibilidad de adecuación de la Constitución Histórica de Navarra al nuevo orden liberal dado que este, tal y como se vió en aquel artículo, zanjó el asunto excluyendo explícitamente del proceso de jura de la Constitución al legislativo navarro con el argumento de que las Cortes de Navarra eran legislativas y que, por ello, no "debia permitirse la instalación de las Cortes de Navarra, pues esto seria hacer compatibles dos Cuerpos legislativos en un mismo Estado". En el plano empírico la imposibilidad de reunión de dicha asamblea legislativa suponía la supresión de la Diputación que dimanaba de ella y de todo el orden constitucional foral. Con todo, hay que recordar que, según se dijo en aquel artículo, no hay ningún indicio de que hipotéticos simpatizantes del constitucionalismo gaditano residentes en Navarra o relacionados con Navarra hicieran propuestas de conciliación entre el constitucionalismo foral navarro y el nuevo orden que surgía en el Estado. Además, como también se vió, las elecciones a diputados a Cortes y a la Diputación Provincial efectuadas en Navarra en septiembre de 1813 traslucieron un marcado control por parte de los absolutistas y de los realistas moderados del escenario politico navarro, siendo prácticamente residual la presencia de liberales en dicho proceso electoral, lo que dificultaba cualquier entendimiento.

En 1820 hubo una propuesta de conciliación entre el orden constitucional liberal y el orden tradicional foral navarro. A mediados de marzo de 1820, con la reinstauración de la Constitución de 1812, un ilustre liberal navarro, el síndico del reino Florencio García Goyena ${ }^{35}$, planteó la convocatoria inmediata de las Cortes

$34 \quad$ Fernando Mikelarena Peña, "Las apelaciones ante las asambleas parlamentarias españolas al respeto a la Constitución histórica propia por parte de la Diputación de Navarra en Bayona y Cádiz”, Historia Constitucional, Revista Electrónica de Historia Constitucional, 16, 2015, pp. 133-176

35 En 1820-1823 y tras 1834 ocuparía cargos importantes dentro de la carrera política y judicial llegando a la presidencia del Tribunal Supremo en 1843 y a ser Ministro de Gracia y Justicia y Presidente del Gobierno en 184. Puede verse su biografia en Enciclopedia de Historia de España, vol IV. Diccionario biográfico, Madrid, Alianza Editorial, 1991, pp. 344-345. Disponible en Internet en la dirección http://www.xtec.es/ jrovira6/bio/gargoyen.htm. 
navarras por parte del Gobierno con el "efecto solo de tratar de su incorporación lisa y llana con absoluta igualdad y unidad bajo el nuevo Régimen constitucional al resto de la Monarquía". Para García Goyena, los navarros se adheririan al ofrecimiento de forma "voluntaria, sincera y durable", y se unirian "gustosos a la gran familia española" 36 . En relación con esa opción, en octubre de 1839, en el contexto del debate registrado en el Senado en relación con la ley que se aprobaría el 25 de ese mes relativa a la foralidad vasconavarra, el conde de Ezpeleta recordaría que en 1820 Florencio Garcia Goyena "estaba de diputado en Madrid, y la hizo, por cierto confidencial, al Sr. Sancho, con el objeto de que se reuniesen las Cortes de Navarra con el único objeto de tratar de la incorporación, para que fuese más legal y para que en ningún tiempo se pudiese reclamar; pero sucedieron los acontecimientos que son bien sabidos, y como yo me hallaba de guarnición en Pamplona cuando se pronunció, sé que no hubo lugar a nada y la cosa quedó en tal estado"37.

En mayo de 1834 dos liberales moderados, ambos miembros de la Diputación del Reino, el barón de Bigüézal (futuro conde de Guenduláin), y Martínez de Arizala, también se hicieron eco de los problemas de compatibilidad entre la Constitución Histórica de Navarra y el nuevo constitucionalismo liberal. En una Representación, leída en la sesión de la Diputación de 17 de mayo de 1834 y redactada en relación con la convocatoria de Navarra a las Cortes de España para ser remitida al Presidente del Consejo de Ministros, sostuvieron que la Diputación no podía admitir tal orden de convocatoria de Navarra a las Cortes Españolas por ser contraria a los fueros ${ }^{38}$. En la carta que Arizala y Bigüezal remitieron el 28 de mayo de 1834, y que fue leída en la sesión de la Diputación de 6 de junio, aquéllos informaban que la extensión de la convocatoria de Cortes también a Navarra venía a suponer que, a su juicio, al ser el Reino navarro "convocado a un cuerpo legislativo estraño para él por las leyes y por la práctica", "de hecho espira su cuerpo legislativo propio, y por consiguiente sus leyes particulares" y "por consecuencia precisa, concluye la representación conservadora, o sea Diputación nombrada por sus Cortes, y que deberia tener fin en la reunión de otras cortes propias". Abundando en esas ideas, enjuiciaban que "la Diputación actual intimada a elegir diputados o procuradores para las Cortes generales de España, deja de existir en el mismo hecho de organizarse un nuevo cuerpo legislativo incompatible con su existencia, y por consiguiente debe manifestar al Gobierno su fin y disolución, antes de pasar a una elección que produciría anomalias e ilegalidades equívocas y poco dignas de nuestro honor y nuestro nombre". Arizala y Bigüézal se inclinaban porque la Diputación elevara una "protesta respetuosa" acompañada de su dimisión a espera de que en el futuro el gobierno se mostrara más receptivo con las instituciones navarras. Con

36 Archivo General de Navarra (AGN), Reino, Diputación del Reino, sus Síndicos y Secretario, Gefes políticos y Diputaciones Provinciales, Legajo 3, Carpeta 33. Cartas del Síndico don Florencio Garcia comisionado en Madrid comunicando a la Diputación sus ideas sobre la conducta que convendria seguir en Navarra con motivo de haberse restablecido la Constitución española (1820).

37 “Los fueros de las Provincias Vascongadas y Navarra en las Cortes de 1839", Documentación Administrativa, 1977, 175, pp. 376-377. Dicho artículo recoge la transcripción de todos los textos de los diarios de las sesiones del Congreso de los Diputados y del Senado relativos al debate de la ley de 1839, con la sola excepción de los relativos a cuestiones incidentales que no tocan la sustancia del mismo.

38 AGN, Reino, Actas de la Diputación, Libro 39, desde 13 de septiembre de 1833 a 10 de agosto de 1834, ff. 176r-177r. 
el fin de paliar los perjuicios a nivel administrativo ocasionados por tal dimisión de los miembros de la corporación, recomendaban que se constituyeran juntas particulares "que quedasen en custodia y manejo de sus respectivos intereses". $\mathrm{Su}$ recomendación estaba acompañada de una reflexión referida a las Diputaciones de las tres provincias vascongadas, que, siendo "más flexibles por su instituto, y menos revestidos del carácter delicado de delegados de un cuerpo legislativo, transigen más fácilmente con las alteraciones y disfrutan no pocas veces por este medio de ventajas efectivas y reales"39.

En sus Memorias el mismo Bigüézal recordaría cómo había defendido en 1834, con ocasión de la convocatoria de elecciones para las Cortes Estamentales del Estatuto Real, la consideración de Navarra como reino distinto y separado en leyes y territorio al ser el redactor de las representaciones presentadas por la Diputación entonces en Madrid. Señalaba alli que en un primer texto había apoyado "que Navarra no fuese convocada como las demás provincias, y para que en tiempo oportuno, convocadas sus propias Cortes, determinasen éstas la forma y modo de continuar en adelante, ora estableciendo medios de conservar entrambas Constituciones, ora dictando reglas y concertando arreglos para una incorporación legislativa por los únicos medios legales posibles". Asimismo, indicaba que en un segundo memorial había expuesto "todos los principales puntos de la Constitución o Fueros de Navarra", protestando "la convocatoria como incompatible con la existencia de nuestras Leyes fundamentales" 40.

Aunque la Diputación inicialmente se hizo eco de los argumentos de Bigüézal, al final tuvo que aceptar los requerimientos del comisionado regio Gerónimo de la Torre que solicitaba el cumplimiento del Estatuto Real y de los Reales Decretos de convocatoria a Cortes, fijándose las elecciones para el 30 de junio ${ }^{41}$.

Más adelante, en la coyuntura del debate de la ley de octubre de 1839, otro autor recordaría en un opúsculo la necesidad, porque así lo ordenaban los cánones de la constitución histórica de Navarra, de contar con el legislativo navarro para los cambios politicoinstitucionales que fueran a producirse. Ese folleto fue obra de Ángel Sagaseta de Ilurdoz y tenía como título Fueros fundamentales del reino de Navarra y Defensa legal de los mismos. Esta obra conoció dos ediciones, una publicada en Valencia el 21 de diciembre de 183942 y otra, de reedición de la anterior, publicada en Pamplona en 1840 en la imprenta de Francisco de Erasun. Ambas ediciones fueron secuestradas por las autoridades, hasta el punto de que se conservan poquísimos ejemplares en bibliotecas públicas o en bibliotecas privadas catalogadas por la administración, aunque hoy día está en Internet.

\footnotetext{
39 Ibid., ff. 194v-196v.
}

40 Memorias de D. Joaquin Ygnacio Mencos, Conde de Guendulain, 1799-1882, Pamplona: Diputación Foral de Navarra-Institución Príncipe de Viana, 1952, pp. 94-95. La primera representación se publicó en El Piloto el 5 de octubre de 1839 . Detalles sobre el asunto se dan en Rodrigo Rodriguez Garraza, Navarra de reino a provincia (1828-1841), Pamplona: Eunsa/Institución Príncipe de Viana, 1968, pp. 181-184.

41 "Los fueros de las Provincias Vascongadas y Navarra en las Cortes de 1839", op. cit., 206v210 r.

42 Esta edición es la que manejó y transcribió Hermilio de Olóriz en Navarra en la guerra de la Independencia. Biografía del guerrillero D. Francisco Espoz y Noticia de la abolición y restablecimiento del régimen foral, Pamplona, 1910, pp. 443-456. 
Hay que señalar que en el debate reintegracionista de 1918 los carlistas más radicales no se limitarán a manejar los argumentos de Sagaseta. A partir del 22 de diciembre de 1918 El Pensamiento Navarro y a lo largo de los días posteriores publicará su opúsculo en toda su integridad.

Ángel Sagaseta de Ilurdoz fue Síndico Consultor de las Cortes de Navarra desde 1817 hasta 1833, fecha en que fue desterrado a Valencia por sus simpatias con el carlismo y por sus estrechos vínculos con militares carlistas como Zumalacárregui o Zaratiegui ${ }^{43}$. Sus simpatías por la reacción en $1820-1823$ y por el carlismo a partir de 1833 fueron compatibles con una ferviente defensa, desde su puesto de síndico, de las competencias de las instituciones navarras frente a las pretensiones de recorte de las mismas por parte de los gobiernos absolutistas de Fernando VII hasta el punto de que Sáinz de Andino, entre las medidas que recomendó para efectuar el traslado de las aduanas sin contar con las Cortes, y para neutralizar la acción de los comisionados navarros y de los sectores opuestos al traslado, aconsejó el confinamiento por separado, entre otros, de Sagaseta, tachándolo de ser hombre taimado, intrigante y tenaz, y de haberse mostrado abiertamente desobediente y arrogante en las Cortes navarras ${ }^{44}$. Con ocasión de la sublevación de O’Donnell no fue incluído en la nómina de 94 condenados a muerte en ausencia, pero si entre los 63 civiles desterrados de Navarra, llegándose en ella a decir de él que es "carlista consumado y hombre de mucha influencia por sus relaciones y riqueza. Fue desterrado en la guerra anterior por su mala conducta política y por ser íntimo amigo de Zumalacárregui [, siendo] el autor del folleto incendiario en favor de los fueros netos, que se recojió por el Gefe Político Arteta"45. Falleció el 23 de mayo de 1843 a los 59 años.

El folleto de Sagaseta se articula en dos partes bien diferenciadas. En una primera, titulada Fueros Fundamentales del Reino de Navarra viene a reconstruir los que serian los principios fundamentales de la constitución histórica de Navarra en relación con diferentes aspectos. La segunda parte, titulada Defensa legal de los fueros y constitución del Reino de Navarra, viene a representar un alegato a favor de la necesidad de enfocar la negociación para la modificación foral como algo a sustanciar entre dos reinos situados a la misma altura.

En esa segunda parte del folleto, Sagaseta remarca, tras citar diversas frases de algunos intervinientes en el debate de la ley de octubre de 1839, que, según el principio de posesión, los fueros navarros debían haberse reconocido integra y completamente por parte de las Cortes españolas, sin perjuicio de que éstas

43 Datos biográficos de Sagaseta en Hermilio de Olóriz, Navarra en la guerra de la Independencia. Biografía del guerrillero D. Francisco Espoz y Noticia de la abolición y restablecimiento del régimen foral, op. cit.., pp. 441-444; en Joseba Agirreazkuénaga (Et. al.), Diccionario biográfico de los parlamentarios de Vasconia (1808-1876), Vitoria, Parlamento vasco, 1993, pp. 816-818 y en Fernando Mikelarena, "El foralismo radical de Ángel Sagaseta de Ilurdoz ante el absolutismo centralizador de Fernando VIP', Tiempos Modernos. Revista Electrónica de Historia Moderna, 34, 2017, pp. 278-281.

44 Ramón del Río Aldaz, Las últimas Cortes del Reino de Navarra (1828-1829), Pamplona, Haranburu, 1985, pp. 311-312; Juan Cruz Alli Aranguren, "Pedro Sáinz de Andino y el traslado de las aduanas del Ebro al Pirineo", Principe de Viana, 232, 2004, pp. 539-540; Fernando Mikelarena, "El foralismo radical de Ángel Sagaseta de Ilurdoz ante el absolutismo centralizador de Fernando VIP”, op. cit., pp. 283-293.

45 La documentación se encuentra en Archivo Municipal de Pamplona (AMP), Guerra, Milicia Nacional, Legajo 168, documento 135. 
pudieran haber reconvenido a las instituciones navarras para que la utilización de la foralidad tuviera en cuenta la "libertad nacional" de los españoles y de que se considerase lo que podía tener "más cuenta" en aras de "formar una misma familia". Posteriormente, Sagaseta defiende con argumentos históricos el carácter de eqüeprincipal de la unión de Navarra con el resto de la monarquía. Siendo el Reino de Navarra reino de por sí, siendo una monarquía constitucional y estando unido a la Corona de Castilla eqüeprincipalmente, Sagaseta concluye que "ningún otro reino, por estenso que sea, por formidable que aparezca, tiene derecho para dictar providencias al mismo, introducir novedades, confirmar ni modificar sus Fueros o Constitución, sujetarlos a convenio, ni variar la Diputación permanente, sean todo lo defectuosos que se quiera, necesiten enhorabuena reformas, reclámenlas imperiosamente las tan ponderadas luces del siglo: todo ello será peculiar y privativo de los tres Estados de dicho reino, obrando por sí solos, sin fuerza, sin intervención, sin concurso de ningún otro reino". En apoyo de sus posiciones, Sagaseta alude a la existencia de monarquías constitucionales confederadas en Europa, citando el ejemplo de Suecia y Noruega.

Tras recordar un dictamen del marqués de las Amarillas presentado en marzo de 1834 al Consejo de Gobierno y publicado en El Correo Nacional el 3 de octubre de 1839 a favor de la convocatoria separada de las Cortes navarras para la aprobación del Estatuto Real, en su corolario, Sagaseta finaliza afirmando que "Si Navarra necesita reformas, si le conviene variar su Constitución, y establecer nueva unión con la Corona de Castilla lo sabrán hacer sus tres Estados: no hay otro medio justo, legítimo, estable y político. El Reino de Navarra legítimamente congregado no ha autorizado a persona ni corporación alguna para que pueda variar sus Fueros: no necesita que nadie por autoridad propia le introduzca mejoras, aunque sean reales y efectivas: tiene derecho de gobernarse de por sí, y tiene dadas pruebas inequivocas de que sabe adoptar las medidas que reclaman las luces del siglo". Con todo, Sagaseta no especificó en absoluto qué elementos del tejido constitucional navarro debían ser reformados, abstrayéndose de las deficiencias internas del mismo y de los factores sociales y económicos como los de la unidad de mercado y de unificación y modernización legislativa que empujaban hacia una mayor integración en el Estado.

Las tesis de Sagaseta serían recordadas en 1843, dos años después de la promulgación de la Ley de 16 de agosto de 1841, y también de la insurrección de O'Donnell de octubre de 1841 en la que, como decimos, se reivindicó la reintegración foral plena 46 . Un folleto publicado por un tal Francisco Javier de Ozcáriz en aquel mismo año y titulado Intereses de navarra. Vindicación de los fueros vasco-navarros. Ecsamen de los mismos como sistema politico, civil, administrativo y económico: cuestión legall7 recogía una polémica mantenida en la

\footnotetext{
46 Además de estar presente dicha reivindicación en la proclamas de los militares alzados en Vascongadas y en Navarra (primordialmente Montes de Oca y el propio O'Donnell), el 10 de octubre desde Cizur Mayor el Barón de Bigüezal, mencionado como presidente de la Diputación de Navarra interina, emitía una proclama a los navarros que comenzaba diciendo que la Religión, la Regencia de Maria Cristina "y los fueros de este Reino en toda su integridad, y como los recibisteis de vuestros mayores, son hoy vuestra bandera, son el monumento de vuestra gloria y de vuestro nombre". Cfr. Fernando Mikelarena Peña, "La sublevación de O’Donnell de octubre de 1841 en Navarra", op. cit., pp. 260-261.
}

47 Intereses de Navarra. Vindicación de los fueros vasco-navarros. Ecsamen de los mismos como sistema político, civil, administrativo y económico: cuestión legal por d. Francisco Javier de 
prensa navarra entre aquel, Pablo Ilarregui y José Yanguas y Miranda, estos dos últimos negociadores de la ley de agosto de 1841. En ese folleto Ozcáriz se muestra seguidor de las tesis de Sagaseta al subrayar la ilegitimidad del proceso de modificación de fueros que desembocó en la ley de agosto e 1841 al no haber intervenido las Cortes navarras. Con todo, Ozcáriz comprendia que las necesidades del pueblo navarro habian variado y no queriendo "que permanezca estacionario" ni entendiendo "por incompatibles sus fueros con su estado actual y con su progreso", no se oponía "a que se acomoden a estos por los medios que le ofrecen los mismos fueros, pero sin salirse de ellos, sin destruirlos" 48 . Pero tampoco, al igual que Sagaseta, proporcionaba detalles concretos sobre cómo debía llevarse a cabo esa conciliación.

La memoria, esgrimida por los carlistas más radicales, de los argumentos de Sagaseta y de otros autores en relación con la necesidad de convocatoria de las Cortes estamentales navarras a la altura de 1918 en el caso de que, tal y como se solicitaba por parte del ayuntamiento de Pamplona y de la inmensa mayoría de los ayuntamientos navarros, se derogara la ley de octubre de 1839, chocaba con una desmemoria y con el olvido: el relativo a los argumentos utilizados repetidamente por diversos autores durante la primera mitad del siglo XIX acerca de las deficiencias de las instituciones tradicionales navarras y, sobre todo, de las Cortes estamentales. Además, por supuesto, la desmemoria se ampliaba con el olvido del eje central de la incompatibilidad entre el constitucionalismo liberal y el constitucionalismo historicista navarro: la negativa del primero, explicitada tajantemente por las Cortes de Cádiz en agosto de 1813, a admitir un segundo cuerpo legislativo en Navarra.

Desde finales de 1835 los liberales progresistas navarros comenzaron a presentar sus argumentos opuestos al mantenimiento del régimen foral, basándose en las deficiencias de las instituciones navarras, a su juicio, imposibles de subsanar. Los días 1, 5 y 12 de noviembre de aquel año se publicó en el Boletín Oficial de Pamplona un artículo firmado por F. B. en el que se recoge una supuesta conversación entre un joven liberal y un anciano. En él, se arremetía duramente contra las instituciones navarras. Acerca de las Cortes se decía que "una cámara compuesta de tres brazos o estamentos de cuerpos tan eterogéneos y de tan encontrados intereses, sin una verdadera elección popular, mal podía representar las necesidades del país ni avenirse para la adopción de leyes que llevasen el sello de la utilidad general". En otro lugar del texto, el autor manifestaba que la mayoria de los navarros estaban por la homogeneización con el resto de España, pero de todas formas abría la puerta a preguntar a quien estuviera "preocupado en favor de nuestros fueros o que sostuviese ser posible hacer esa reforma con nuestras antiguas instituciones" por los esfuerzos de "nuestra representación nacional" "por la felicidad del país" y por los "abusos de

Ozcáriz, Pamplona, por el Regente Zenón Garayoa, 1843. Al igual que sucede con el de Sagaseta, de este folleto solamente se conserva un ejemplar en bibliotecas públicas o privadas catalogadas con fondos públicas, si bien en este caso en el fondo histórico de la biblioteca de la UPNA. Por otra parte, más información acerca de la polémica, sus contenidos y sus protagonistas en Ángel García-Sanz Marcotegui, El fuerismo constitucional y la Diputación de Navarra (1841-1923), op. cit., pp. 76-101.

48 Intereses de Navarra. Vindicación de los fueros vasco-navarros. Ecsamen de los mismos como sistema político, civil, administrativo y económico: cuestión legal por d. Francisco Javier de Ozcáriz, op. cit., p. 41. 
legislación" que hubiera "abolido o remediado" y por las "reglas" que hubiera "adoptado para afianzar nuestra libertad civil, nuestra seguridad personal, nuestra propiedad y los demás derechos que constituyen la perfección social”.

Unos meses más tarde, José Alonso Ruiz de Conejares subrayaba de forma más detallada en El Eco del Comercio del 26 y el 27 de mayo de 1836 las deficiencias de la Constitución histórica de Navarra ${ }^{49}$. Alonso subrayaba que la constitución y la legislación de Navarra estaban "fundadas sobre el monstruoso sistema feudal y dirigidas únicamente a favorecer a las clases del clero y la nobleza, imponiendo más trabas y gravámenes a la agricultura, industria y comercio de los navarros, que el sistema de Castilla a los habitantes de sus provincias". Alonso reseñaba la supeditación de las Cortes y la Diputación a los intereses de las clases privilegiadas, y, sobre todo, a los del clero.

Un año después, en 1837, Yanguas y Miranda presentaba, en un opúsculo que se correspondía con el prólogo que había hecho a la obra de Correa sobre la conquista de Navarra ${ }^{50}$, la primera versión de su discurso, ya más estructurado al año siguiente, sobre el atolladero o callejón sin salida que suponía, según él, recurrir a las Cortes navarras para sancionar cualquier modificación del status politicoinstitucional navarro a causa de los problemas que generaría la estructura estamental de aquéllas y la capacidad de veto que en ellas tenía el brazo clerical, conformado por el alto clero. Asimismo, presentaba también su propuesta de solución o del nudo gordiano: la modificación debería efectuarse mediante otras vías alternativas, fuera mediante la representación navarra en las Cortes españolas o fuera mediante una Diputación provincial, libre ya de las ataduras que obligaban a la extinta Diputación del Reino, existente hasta 1837, por su carácter de ser un órgano de representación permanente de un cuerpo legislativo.

Yanguas volvió a presentar sus tesis en diversos formatos en 1838. El primero, la Representación de 5 de marzo de 1838 remitida por la Diputación provincial de Navarra a las Cortes españolas ${ }^{51}$. Al contrario de las Juntas Generales de las Provincias Vascongadas, en Navarra, donde las Cortes actuaban sobre "lo civil, lo económico y administrativo, y todos los ramos que constituyen el gobierno de una monarquía" y donde no podia resolverse cuestión alguna "sin que la pluralidad absoluta de cada uno de los tres estamentos vote por la afirmativa", el estamento eclesiástico era "siempre un escollo donde se estrellarán todos los conatos hacia las mejoras que reclaman las luces del siglo" porque "cinco o seis monjes son suficientes para impedir enteramente que se lleve a cabo la resolución más útil y mejor meditada". Además, por lo que respecta a los otros dos estamentos, "el brazo de la nobleza, aunque más ilustrado, más adherido a los intereses públicos, y más generoso en transigir con ellos, está constreñido del todo por el eclesiástico, y el estamento del pueblo no puede adelantar un paso hacia el bien, bajo semejante sistema representatibo".

49 A pesar de no estar firmado, el texto se corresponde con el discurso que Alonso pronunció en el Estamento de Procuradores el 17 de mayo con ocasión del debate sobre el artículo 55 de la ley electoral, según el editorial del mismo periódico del día 18 de mayo.

50 José Yanguas y Miranda, Prólogo sin libro sobre la monarquía navarra: copiado de los boletines de Pamplona, Pamplona: Imprenta de Ramón Domingo, 1837.

51 Dicha representación se encuentra en AGN, Sección de Administración Provincial, Libros de Actas de la Diputación Provincial de Navarra, Libro de actas de 28 de diciembre de 1836 a 23 de abril de 1838, ff. 253r-261r. 
El segundo formato en el que Yanguas presentó sus tesis fue por medio de un folleto, el Análisis Histórico Crítico de los Fueros de Navarra, publicado en la imprenta pamplonesa de Francisco Erasun, pero también difundido en la prensa periódica, tanto en el Boletín Oficial de Pamplona (15 19, 22, 26 y 29 de marzo, así como el 2 de abril de 1838) como en el periódico madrileño El Eco del Comercio, órgano del progresismo (15, 16, 17 y 19 de marzo de 1839). Para el erudito liberal tudelano, los defectos de las instituciones navarras, "tanto esenciales como politicos y abusivos", hacian que la Constitución navarra fuera "ilusoria y aun perjudicial e inaplicable a las circunstancias del dia". El modo de funcionamiento conservador de las Cortes navarras hacía que "con él nada se podía adelantar en las mejoras legislativas que exigía la conveniencia de los pueblos". El principal defecto del legislativo navarro era el estamento del clero, que "era constantemente un escollo donde se estrellaban las mejores intenciones de la mayoría del congreso: jamás podía votar por ninguna novedad que tuviese tendencia hacia la ilustración, porque es la que hacía la guerra a sus abusos y a su perjudicial preponderancia sobre las otras clases". A su vez, el estamento de las universidades tenía graves problemas de representatividad, sobre todo, porque "muchos pueblos de corto vecindario tenían voto en cortes, y dejaban de tenerlo otros de mayor población" y "entre los que le tenían, era igual la representación de uno de 90 vecinos a otro de 2.600, como sucedía con Villava y Pamplona". Por todo ello, Yanguas juzgaba como inviable en la práctica la posibilidad teórica de reforma de las Cortes navarras, tanto por las inercias de los mismos estamentos como por la imposibilidad de que pudiera cuajar en Navarra una revolución popular que alterase las esencias constitutivas de aquéllas. En la conclusión final del folleto Yanguas no dejaba de mencionar el problema procedimental al que se enfrentaba la cuestión de la reforma del régimen foral, cuestión que ya se había planteado en Bayona y en Cádiz. Aunque técnicamente la constitución de Navarra no podía "alterarse sino en sus cortes generales", subrayaba que también era obvio por las razones expresadas más arriba "que no podia esperarse este bien del voto de los antiguos estamentos".

En el mismo debate en las Cortes sobre la ley de 25 de octubre de 1839, tanto del proyecto de ley remitido por el gobierno como de los dos dictámenes de la comisión se desprende que nunca se vislumbró la eventualidad de resurrección de los órganos inherentes a la constitución histórica de Navarra (es decir, Cortes y Diputación, entendida ésta última como representación permanente de aquéllas) por contemplarse la tesis de su incompatibilidad con el orden constitucional y la imposibilidad de su reforma. Así, el diputado aragonés Iñigo subrayó la "contraposición con los principios constitucionales" de "la convocación a Cortes en Navarra"52. Asimismo, el diputado aragonés Javier Quinto, que habia suscrito el dictamen de la minoría de la comisión, juzgó que no se podían confirmar los fueros políticos por el grado de perjuicio que se inferiría "señaladamente a Navarra" ya que "los derechos políticos de las sociedades modernas son mucho más amplios, más generosos que los de las épocas de donde proviene la legislación foral"53.

52 "Los fueros de las Provincias Vascongadas y Navarra en las Cortes de 1839", op. cit., pp. 133-134.

53 Ibid., pp. 199-205. 
En el Senado los requerimientos de Viluma para que Arrazola explicara el sentido de la expresión unidad constitucional dieron lugar a una intervención del segundo el 19 de octubre que indicaba la imposibilidad de resurrección de las instituciones navarras en cuanto que entendia aquella a partir de la existencia de un único poder legislativo ${ }^{54}$. Intervenciones posteriores se refirieron a ese aspecto expresado por Arrazola y a su consecuencia para el núcleo de la posibilidad de mantenimiento de la constitución histórica navarra. Así, el conde de Ezpeleta, miembro de la comisión y que había votado a favor del dictamen con la mayoría de la misma, en una primera intervención indicó la imposibilidad de que "hubiera Cortes en Navarra"55. El marqués de Vallgornera definió el concepto de unidad constitucional en conformidad con Arrazola afirmando que era "la del Poder legislativo; esto es que sean unas las Cortes, unos los Poderes supremos del Estado que concurren a la formación de las leyes (...). No habrá otras Cortes que las del Reino"56. Antonio González, futuro Presidente del Consejo de Ministros en la Regencia de Espartero, hizo una larga exposición sobre el régimen foral navarro basada en las tesis de Yanguas acerca de las deficiencias de las instituciones navarras. Por los defectos de las Cortes navarras y por la superioridad de las Cortes constitucionales españolas, era imposible la convocatoria de aquellas "y autorizar un poder contra el cual no hubiese término ni defensa alguna". González defendía "un poder constitucional y responsable de sus actos con sujeción a las leyes" y "que la potestad de hacer las leyes únicamente resida en las Cortes con el Rey, y que fuera de aquí no haya tal facultad en ninguna corporación"57. El mismo Viluma negó que él quisiera "restablecer las Cortes de Navarra" y que su objeto fuera "restablecer lo que no se puede restablecer, ni dar facultades al clero en las Cortes de Navarra: yo sé que eso no se restablece ni se puede restablecer"58. Asimismo, Maciá Lleopart llegó a preguntar en una intervención: “¿Cómo puede sin el mayor absurdo suponerse posible que en Navarra se haya pensado ni se piense en que se restablezcan por poco ni mucho tiempo sus antiguas Cortes, formando un país separado dentro de la Nación?"59.

Finalmente el real decreto de 16 de noviembre de 1839 sancionaría los puntos de vista de Yanguas al establecer la forma de implementación del artículo segundo de la Ley de 25 de octubre, esto es, para que se pudiera llevar a cabo el trámite de audiencia de Navarra y Vascongadas necesario para la elaboración de la propuesta de modificación de los fueros que el Gobierno debía presentar a las Cortes. Mientras, por el artículo primero, se resucitaba el sistema foral tradicional en las provincias de Álava, Guipúzcoa y Vizcaya, ordenándose que se constituyeran sus respectivas Juntas Generales para elegir a sus Diputaciones, en lo que respecta a Navarra, según el artículo cuarto, se establecía que la Diputación, ya no del Reino, debía ser nombrada según los parámetros constitucionales fijados para la elección de las diputaciones provinciales, si bien

\footnotetext{
$54 \quad$ Ibid., pp. 278-284.

$55 \quad$ Ibid., pp. 291-294.

56 Ibid., pp. 314-321.

57 Ibid., pp. 348-359.

$58 \quad$ Ibid., p. 359.

$59 \quad$ Ibid., p. 363.
} 
con algunas peculiaridades en su composición y competencias que recordaban en cierto modo a la corporación extinguida. Por otra parte, según el artículo séptimo se determinaba, en conformidad con todo lo anterior, una clara diferenciación entre los protagonistas de la interlocución con el gobierno de Madrid: en Vascongadas serian las Juntas Generales las que nombrarian los "dos o más individuos que unos a otros se sustituyan" para conferenciar con aquél; en cambio, en Navarra los designaría "la nueva diputación", convirtiéndose ésta en el árbitro del proceso para dicho territorio. Esa Diputación sería elegida por un sufragio fuertemente censitario en un escenario politico en el que los diputados elegibles pertenecerian bien al liberalismo moderado, bien al progresista, permaneciendo fuera de juego, por proscripción política tácita, otros posibles candidatos adscritos al carlismo, el sector predominante entre la opinión pública navarra ${ }^{60}$.

Fecha de envío / Submission date: 14/11/2018

Fecha de aceptación / Acceptance date: 3/01/2019

60 En el periodo 1839-1843 no hay ningún carlista entre los diputado a Cortes y los diputados provinciales elegidos, siendo dudoso que presentaran candidatos (Cfr. Ángel GarcíaSanz Marcotegui, Diccionario biográfico de los diputados forales de Navarra (1840-1931), op. cit.; Ángel García-Sanz Marcotegui, El fuerismo constitucional y la Diputación de Navarra (1841-1923), op. cit., pp. 39-44). De cualquier forma, El Eco del Comercio el 11 y el 19 de septiembre de 1844 informaba que los carlistas habian ganado en las elecciones generales de aquel mes en la mayoría de los distritos de Pamplona y de Estella, pero que los moderados consiguieron la anulación de aquellas actas y la proclamación de sus candidatos. 